\title{
Synthesis and biomedical applications of nanoceria, a redox active nanoparticle
}

\author{
Neelam Thakur ${ }^{1}$, Prasenjit Manna2* $2^{*}$ and Joydeep Das ${ }^{1 *}$
}

\begin{abstract}
Background: Nanoceria has recently received much attention, because of its widespread biomedical applications, including antibacterial, antioxidant and anticancer activity, drug/gene delivery systems, anti-diabetic property, and tissue engineering.

Main body: Nanoceria exhibits excellent antibacterial activity against both Gram-positive and Gram-negative bacteria via the generation of reactive oxygen species (ROS). In healthy cells, it acts as an antioxidant by scavenging ROS (at physiological pH). Thus, it protects them, while in cancer cells (under low pH environment) it acts as pro-oxidant by generating ROS and kills them. Nanoceria has also been effectively used as a carrier for targeted drug and gene delivery in vitro and in vivo models. Besides, nanoceria can also act as an antidiabetic agent and confer protection towards diabetes-associated organ pathophysiology via decreasing the ROS level in diabetic subjects. Nanoceria also possesses excellent potential in the field of tissue engineering. In this review, firstly, we have discussed the different methods used for the synthesis of nanoceria as these are very important to control the size, shape and $\mathrm{Ce}^{3+} / \mathrm{Ce}^{4+}$ ratio of the particles upon which the physical, chemical, and biological properties depend. Secondly, we have extensively reviewed the different biomedical applications of nanoceria with probable mechanisms based on the literature reports.
\end{abstract}

Conclusion: The outcome of this review will improve the understanding about the different synthetic procedures and biomedical applications of nanoceria, which should, in turn, lead to the design of novel clinical interventions associated with various health disorders.

Keywords: Nanoceria, Antibacterial activity, Antioxidant activity, Anti-cancer activity, Drug/gene delivery, Antidiabetic effect

\section{Introduction}

In recent years, there has been a significant advancement in the area of nanotechnology. Due to this, nanoparticles have received much attention in various fields such as in the environmental, industrial, and medical fields. Nanoparticles are the particles having size ranges between 1 and $100 \mathrm{~nm}$. These particles possess unique properties such as small particle size, particle shape,

\footnotetext{
*Correspondence: pmanna2012@gmail.com;

joydeepdas@shooliniuniversity.com; jdchem83@gmail.com

${ }^{1}$ School of Chemistry, Shoolini University of Biotechnology

and Management Sciences, Bajhol, PO Sultanpur, Distt., Solan 173229, HP, India

${ }^{2}$ Biological Science and Technology Division, CSIR-North East Institute

of Science and Technology, Jorhat, Assam 785006, India
}

higher surface area to volume ratio and have different electronic, magnetic, mechanical and optical properties compared to the bulk materials [1]. Nanoparticles should not be considered as a homogeneous group, as it includes a wide range of different materials having different physical and chemical properties. So, there are several types of nanoparticles such as: Fullerenes (C60, C70), carbon nanotubes (Multi-walled and Singlewalled), various types of Metals ( $\mathrm{Au}, \mathrm{Ag}$ ), Metal oxides $\left(\mathrm{ZnO}_{2}, \mathrm{CeO}_{2}, \mathrm{TiO}_{2}\right)$, Quantum dots $(\mathrm{CdSe}, \mathrm{CdTe})[2]$, Liposomes, Dendrimers, Albumin-bound NPs, Polymeric NPs [3], Micelles [4], and Magnetic NPs [5]. There are two main approaches for the synthesis of nanoparticles: the top-down approach and the bottomup approach. In the top-down approach, nanoparticles 
are prepared by decomposition of the larger molecule into smaller units which further form nanoparticles. This approach is also known as a destructive approach. Examples of this approach are grinding, physical vapor deposition, and chemical etching and various other decomposition techniques. While in the bottom-up approach, nanoparticles are prepared from elementary substances, and this approach is also known as building up approach. Examples of this approach are sedimentation, chemical vapor deposition, and various reduction techniques [6]. Nanoparticles show various applications in the biomedical field such as drug and gene delivery, bio-detection of pathogens, detection of proteins, tissue engineering, probing of DNA structure, separation, and purification of biological molecules, tumor destruction via heating and phagokinetic studies [7]. Nanoparticles also show good results in wastewater treatment because of their large surface area and thus helps in the purification of water [8].

Among various nanoparticles, metal oxide nanoparticles are essential and are widely used nowadays due to their unique properties and a large variety of applications in different fields. They are used in cosmetics, sunscreens, textiles, and self-cleaning coatings. These NPs are also widely used as water treatment agents, materials for solar batteries, and as automobile catalytic converters [9]. Some examples of metal oxide nanoparticles are zinc oxide, titanium oxide, iron oxide, cerium oxide nanoparticles, etc. All these metal oxide nanoparticles have their unique properties. Among these metal oxide nanoparticles, cerium oxide nanoparticles (Nanoceria) attract much interest due to its wide range of applications in different areas, especially in the biomedical field.

Cerium is the most abundant rare-earth element of the lanthanide series and found in earth's crust. It can exist in both trivalent and tetravalent state. Cerium can also show stability in the tetravalent state, while other lanthanide elements are stable only in the trivalent state [10]. Cerium oxide or Nanoceria can be regarded as the most critical rare earth metal oxide with its unique ability to switch the oxidation states between $(+3)$ and $(+4)$ depending on the environment [11]. It can exist as both $\mathrm{CeO}_{2}$ and $\mathrm{Ce}_{2} \mathrm{O}_{3}$ in the bulk state [12] and shows catalytic activity due to the redox behavior of cerium [13]. It can adopt a fluorite crystalline lattice structure due to which it has a highly reactive surface area for the neutralization of free radicals [14]. With the decrease in the size of nanoceria, oxygen vacancies are formed in their lattice structure [15] and creating oxygen defects, thereby acting as a free radical scavenger in the physiological environment [16]. Nanoceria has been widely used in various areas such as, in fuel cells [17], optical devices [18], gas sensors [19], catalysis [20], ultraviolet absorbers [21], hydrogen storage materials [22], polishing materials [23], and biomedical fields [24]. However, there are only limited review papers describing the synthetic methodologies and biomedical applications of nanoceria [12, 25-27] and do not provide us complete information about their synthetic methodologies and biological applications. Therefore, in our present review article, we are aiming to combine all of the synthetic strategies along with their biomedical applications.

In this review, firstly, we have discussed various methods that are used to synthesize nanoceria. Among these methods, precipitation method is mostly used while green-synthesis method is advantageous and has given more consideration nowadays as it limits the toxicity of the solvents and reagents used. Then, we focused upon various biomedical applications of nanoceria, particularly the antibacterial activity, antioxidant activity, anticancer activity, drug/gene delivery applications, anti-diabetic activity, and tissue regeneration activity. These unique and extensive biomedical applications of nanoceria are advantageous for the treatment of various types of diseases. In the current review, we have critically analyzed and collected the desired information from previously published research and review papers to show the current state of nanoceria regarding its various biomedical applications. These unique properties of nanoceria will help the scientists and researchers to further explore its applications in the biomedical field.

\section{Synthesis of nanoceria}

There are numerous methods for the synthesis of nanoceria. Those synthesis strategies are fundamental, as the physical and chemical properties of any nanoparticles depend upon them. So, here, we discuss the various methods which have been used to synthesize nanoceria (Fig. 1).

\section{Precipitation method}

Precipitation method is the most convenient technique which has been used by several researchers for the synthesis of nanoceria, as shown in Table 1 . In this method, nanoparticles can be synthesized either at room temperature or at a desired elevated temperature. In the year 1998, Terrible et al. [28] synthesized nanoceria using cerium chloride heptahydrate, cetyltrimethylammonium bromide (CTAB) surfactant and ammonia solution as precursors. The as-synthesized nanoceria (dimensions of 20-50A) were crystalline with high surface area and high thermal stability. Tsai et al. [29] reported the synthesis of nanoceria by homogeneous precipitation method using ammonium cerium nitrate and urea as precursors. The synthesized nanoceria had a cubic structure with the particle size of about $8 \mathrm{~nm}$. 


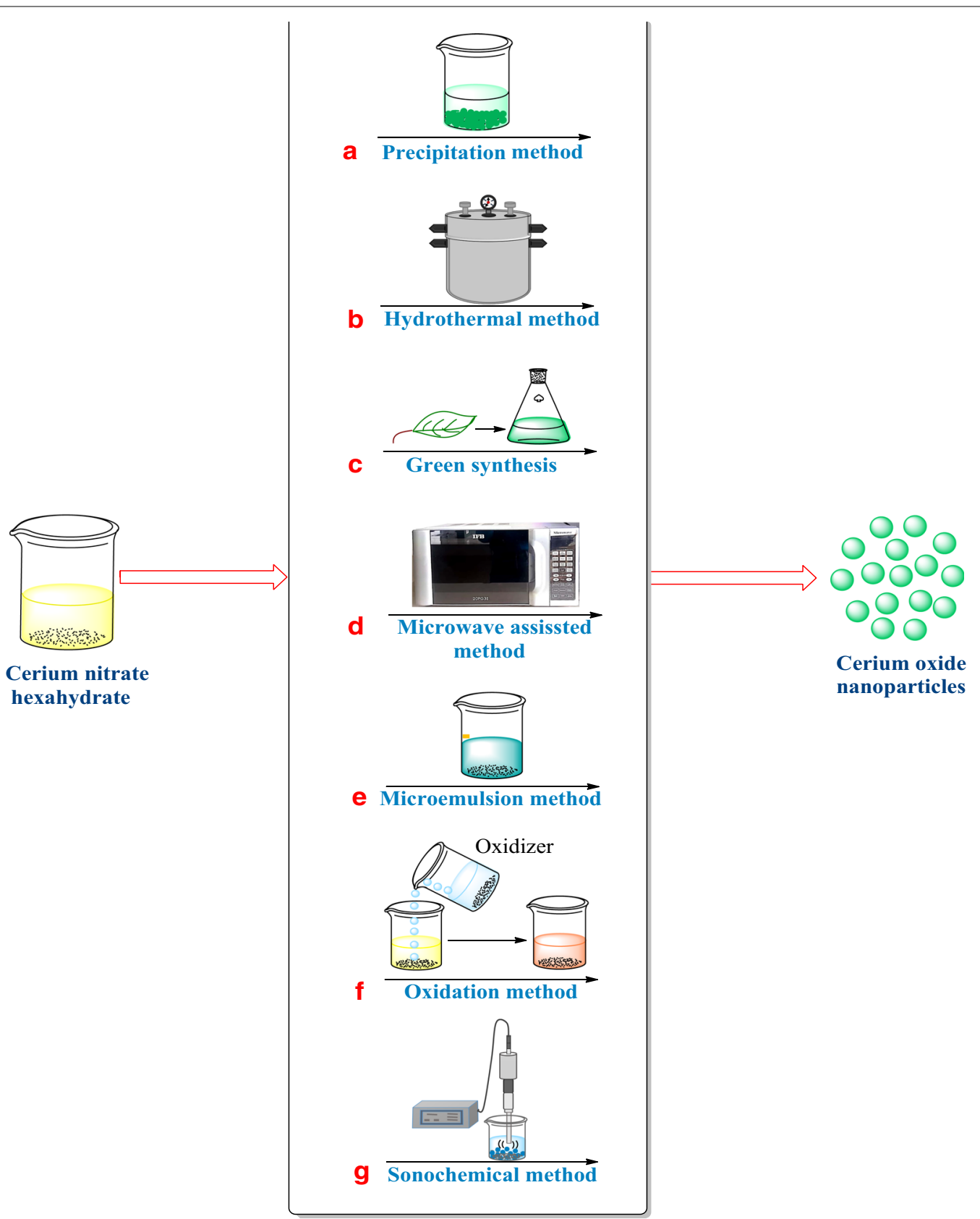

Fig. 1 Different methods for the synthesis of nanoceria. a Precipitation method, $\mathbf{b}$ hydrothermal method, $\mathbf{c}$ green synthesis, $\mathbf{d}$ microwave-assisted method, e micro-emulsion method, $\mathbf{f}$ oxidation method and $\mathbf{g}$ sonochemical method

Most of the researchers used cerium nitrate hexahydrate as the common precursor for nanoceria synthesis in the presence of bases, such as aqueous ammonia, hexamethylenetetramine, $\mathrm{NaOH}$, ammonium carbonate, and potassium carbonate [30-42].

Sun et al. [43] synthesized polycrystalline cerium oxide nanowires from hydrated cerium acetate, sodium bis (2-ethylhexyl) sulfosuccinate and ammonia solution as precursors. The diameter and length of as-prepared nanowires were in the range of $30-120 \mathrm{~nm}$ and $0.2-5 \mu \mathrm{m}$ respectively.

Sujana et al. [44] reported a surfactant mediated precipitation method for the preparation of nanoceria by using cerium nitrate hexahydrate, ammonium 
Table 1 Synthesis of nanoceria by precipitation method

\begin{tabular}{|c|c|c|c|c|}
\hline S. no & Precursors & Medium & Method & References \\
\hline 1. & Cerium chloride heptahydrate, CTAB surfactant, and ammonia solution & Water & Precipitation & {$[28]$} \\
\hline 2. & Ammonium cerium nitrate and urea & Water & Homogeneous precipitation & [29] \\
\hline 3. & $\begin{array}{l}\text { Cerium nitrate hexahydrate, ammonia solution, hydrogen peroxide, and hexa- } \\
\text { methylenetetramine }\end{array}$ & Water & Precipitation & {$[30]$} \\
\hline 4. & $\begin{array}{l}\text { Hydrated Cerium acetate, sodium bis(2-ethylhexyl) sulfosuccinate, ammonia } \\
\text { solution }\end{array}$ & Water and ethanol & Solution phase method & {$[43]$} \\
\hline 5. & Cerium nitrate hexahydrate and sodium hydroxide & Water & Precipitation & {$[31,41]$} \\
\hline 6. & Cerium nitrate hexahydrate, ammonium hydroxide, acetone and tween 80 & $\begin{array}{l}\text { Acetone-water } \\
\text { mixed solvent } \\
\text { system }\end{array}$ & $\begin{array}{l}\text { Surfactant-mediated pre- } \\
\text { cipitation method }\end{array}$ & [44] \\
\hline 7. & Cerium nitrate hexahydrate, dextran and ammonia solution & Water & Precipitation method & {$[35]$} \\
\hline 8. & Cerium nitrate, europium nitrate and ammonium hydroxide $s$ & Water & Co precipitation & {$[36]$} \\
\hline 9. & Cerium nitrate hexahydrate, ammonia and ammonium bicarbonate & Water & Precipitation method & [37] \\
\hline 10. & Cerium nitrate hexahydrate, sodium hydroxide, and polyethylene glycol & Water & Chemical precipitation & {$[38]$} \\
\hline 11. & Cerium nitrate hexahydrate and aqueous ammonia & Water & Homogeneous precipitation & [39] \\
\hline 12. & Cerium chloride heptahydrate, CTAB surfactant, and ammonia solution & Water & Precipitation & {$[45]$} \\
\hline 13. & Cerium nitrate hexahydrate and aqueous ammonia & Water & Precipitation & {$[40]$} \\
\hline 14. & Cerium nitrate hexahydrate, EDTA and ammonium carbonate & Water & Chemical precipitation & {$[42]$} \\
\hline 15. & Cerium nitrate hexahydrate and potassium carbonate & Water & Co-precipitation method & {$[32]$} \\
\hline 16. & Cerium nitrate hexahydrate, polyacrylic acid, and ammonium hydroxide & Water & Precipitation method & [33] \\
\hline 17. & Cerium nitrate hexahydrate and ammonium hydroxide & Water & Precipitation method & [34] \\
\hline 18. & Cerium nitrate hexahydrate, xanthan gum, and ammonia solution & Water & Co-precipitation method & {$[46]$} \\
\hline
\end{tabular}

hydroxide, acetone, and tween 80 surfactants. The synthesized nanoceria showed the average size of about $4.5 \mathrm{~nm}$ with a cubic fluorite structure and exhibited strong room-temperature photoluminescence as well as strong UV absorption. Later, Shelkar et al. [45] reported the synthesis of nanoceria by using cerium chloride hexahydrate, ammonium hydroxide, and CTAB surfactant.

Recently in 2018, Rahdar et al. [46] used a co-precipitation method to synthesize nanoceria from cerium nitrate hexahydrate, xanthan gum, and ammonia solution as precursors. The synthesized nanoceria was spherical having a size of about $20 \mathrm{~nm}$.

All these data and information collected from previous literature showed that the precipitation method was mostly used by the researchers to synthesize nanoceria.

\section{Hydrothermal method}

After precipitation method, this method is most commonly used by many researchers to synthesize nanoceria (Table 2). In the hydrothermal method, water is used as a solvent, and the chemical reaction takes place within

Table 2 Synthesis of nanoceria by hydrothermal method

\begin{tabular}{|c|c|c|c|c|}
\hline S. no & Precursors & Medium & Method & References \\
\hline 1. & Cerium chloride hexahydrate, citric acid, and ammonia water & Water & Hydrothermal crystallization & {$[47]$} \\
\hline 2. & Cerium nitrate and sodium hydroxide & Water & Hydrothermal method & {$[49]$} \\
\hline 3. & Cerium nitrate hexahydrate and sodium hydroxide & Water & Hydrothermal method & {$[50]$} \\
\hline 4. & Cerium nitrate hexahydrate and ammonium hydroxide & Water & Hydrothermal method & {$[53]$} \\
\hline 5. & Cerium nitrate hexahydrate and Polyvinyl pyrrolidone & Water & $\begin{array}{l}\text { Surfactant-assisted hydrothermal } \\
\text { method }\end{array}$ & {$[54]$} \\
\hline 6. & Ceric ammonium nitrate and ammonium carbonate & Water & Hydrothermal method & {$[55]$} \\
\hline 7. & Cerium chloride and ammonium hydroxide & Water & Hydrothermal method & {$[48]$} \\
\hline 8. & Cerium nitrate and sodium hydroxide & Water & Hydrothermal method & {$[51]$} \\
\hline 9. & Cerium nitrate hexahydrate and sodium hydroxide & Water & Hydrothermal method & {$[52]$} \\
\hline
\end{tabular}


autoclave in which the solution is heated under autogenous pressure. The first report of nanoceria synthesis by this technique is registered in 2002 by Masui et al. [47] who used cerium chloride hexahydrate, citric acid, and ammonia water as precursors. The nanoceria prepared under this condition was spherical with an average diameter of $5 \mathrm{~nm}$. Citric acid acted as a protective agent to inhibit particle growth, which is further supported by the study of Renu et al. [48]. They prepared spherical nanoceria having a diameter ranging from 100 to $200 \mathrm{~nm}$ in the absence of citric acids.

Mai et al. [49] synthesized the same using cerium nitrate hexahydrate and sodium hydroxide. In their work, they synthesized nanoceria with three different morphologies; polyhedron having a size of $11.5 \pm 1.8 \mathrm{~nm}$, nanorods having a diameter of $9.6 \pm 1.2 \mathrm{~nm}$ and nanocubes having a size of $36.1 \pm 7.1 \mathrm{~nm}$ by changing the reaction temperature and base concentration. They observed a shape-dependent oxygen storage capacity of the synthesized nanoparticles; nanorods and nanocubes store the oxygen on their surface as well as in bulk, unlike nano polyhedron. After that, several other researchers prepared nanoceria by using the same precursors [50-52] too.

Patil et al. [53] synthesized positively charged nanoceria in the size range $8-10 \mathrm{~nm}$ from cerium nitrate hexahydrate and ammonium hydroxide. Zou et al. [54] reported the surfactant-assisted hydrothermal technique for the synthesis of nanoceria from cerium nitrate hexahydrate and polyvinyl pyrrolidone (PVP) as precursors. In this method, PVP was used as the surfactant. The nanoparticles synthesized were spherical having a diameter in the range of 5-10 $\mathrm{nm}$ and showed electrochemical properties.
Sutradhar et al. [55] used different precursors, such as ceric ammonium nitrate and ammonium carbonate to synthesize nanoceria. The as-prepared nanoceria was spherical having diameter $3-4 \mathrm{~nm}$, possess high surface area, a large number of oxygen vacancies and showed perfect catalytic activity.

\section{Green/bio directed synthesis}

Nowadays, researchers show more interest in Green synthesis approach for the preparation of nanoparticles as described in Table 3. The reason due to which this method has been given more consideration is related to the harmful effects associated with the chemical methods in which toxic chemicals have been used. The green synthesis approach is an easy, safer, reliable, efficient, and environment-friendly method which reduces the use or production of toxic substances. In this method, high temperature, pressure, and energy is not required. The main approaches involved in the synthesis of nanoceria by this method are nutrient-mediated synthesis, plant-mediated synthesis, fungus-mediated synthesis, and polymermediated synthesis [12].

Maensiri et al. [56] used nutrient-mediated synthesis approach for the preparation of nanoceria from cerium acetate hydrate and freshly extracted egg white as precursors. Nanoceria obtained by this method had a plate-like structure having an average diameter of $6-30 \mathrm{~nm}$ and showed excellent thermal, optical, and photoluminescence properties. Later, Kargar et al. [57] also used this approach for the synthesis of nanoceria from cerium nitrate hexahydrate and fresh egg white.

Arumugam et al. [58] used plant-mediated approach to synthesize nanoceria by using Gloriosa superba leaf extract and cerium chloride salt as precursors. The

Table 3 Synthesis of nanoceria by green/bio-directed synthesis

\begin{tabular}{|c|c|c|c|c|}
\hline S. no & Precursors & Medium & Method & References \\
\hline 1. & Cerium(III) acetate hydrate and egg white & Water & Bio-directed synthesis & {$[56]$} \\
\hline 2. & Cerium chloride heptahydrate and Acalypha indica leaf extract & Water & Green approach & {$[59]$} \\
\hline 3. & $\begin{array}{l}\text { Cerium nitrate hexahydrate, gum tragacanth from Astragalus versus and } \\
\text { ammonia solution }\end{array}$ & Water & Gum mediated synthesis & {$[65]$} \\
\hline 4. & Cerium chloride heptahydrate and Curvularia lunata culture filtrate & Water & Mycosynthesis & {$[63]$} \\
\hline 5. & Cerium nitrate hexahydrate and aloe vera leaf extract & Water & Green method & {$[60]$} \\
\hline 6. & Cerium nitrate hexahydrate, starch, and ammonium hydroxide solution & Water & Green synthesis & {$[66]$} \\
\hline 7. & Cerium nitrate hexahydrate and honey & Water & Green synthesis & {$[67]$} \\
\hline 8. & Gloriosa superba leaf extract and cerium chloride salt & Water & Green synthesis & {$[58]$} \\
\hline 9. & Cerium nitrate hexahydrate and fresh egg white & Water & Bio-directed synthesis & {$[57]$} \\
\hline 10. & Cerium nitrate hexahydrate and Hibiscus sabdariffa flower extract & Water & Green synthesis & {$[62]$} \\
\hline 11. & Cerium nitrate hexahydrate and agarose & Water & Bio-organic polymer-based synthesis & {$[64]$} \\
\hline 12. & Cerium nitrate hexahydrate and Olea europaea leaf extract & Water & Green synthesis & {$[61]$} \\
\hline 13. & Cerium nitrate solution, pectin and ammonia solution & Water & Bio polymer mediated synthesis & [68] \\
\hline
\end{tabular}


synthesized nanoceria was spherical with a particle size of $5 \mathrm{~nm}$ and showed antibacterial properties. Other researchers also reported the synthesis of nanoceria by this approach using different plant extracts such as Acalypha indica leaf extract [59], aloe vera leaf extract [60], Olea europaea leaf extract [61] and Hibiscus sabdariffa flower extract [62].

Fungus-mediated approach (Mycosynthesis) is also used by Munusamy et al. [63] to synthesize nanoceria from cerium chloride heptahydrate and Curvularia lunata culture filtrate. The nanoparticles synthesized by this method were tiny in size $(5-20 \mathrm{~nm})$ having a spherical shape and possessed antibacterial activity.

Polymer-mediated synthesis approach has also been taken by some researchers to synthesize nanoceria [6467]. For example, Patil et al. [68] used cerium nitrate, pectin, and ammonia solution as precursors to synthesize nanoceria. The synthesized nanoparticles were spherical having an average particle size of $\leq 40 \mathrm{~nm}$. This nanoceria showed antioxidant and antibacterial properties and was proved non-toxic towards the living tissues.

\section{Oxidation method}

Oxidation method is a direct and straightforward method in which any suitable oxidizing agent (oxidizer) is used to synthesize nanoparticles. The preparation of nanoceria using this method has been adopted by several researchers, as shown in Table 4. Lee et al. [69] synthesized spherical nanoceria in water by simple oxidation of cerium ions using ammonium hydroxide as mineralizer and hydrogen peroxide as an oxidizer. In their work, they reported that the size of nanoceria was decreased with increase in the concentration of the oxidizer. Karakoti et al. [11] reported the synthesis of nanoceria in different biocompatible media such as water, polyethylene glycol, glucose, and dextran solution by using cerium nitrate hexahydrate as precursor while hydrogen peroxide and ammonia as an oxidizer in acidic and basic environment respectively. In comparison with the acidic medium, the nanoparticles synthesized in the primary medium showed less agglomeration. However, in both the conditions the size of synthesized nanoceria remained 3-5 nm. Some other precursors have also been used by different researchers to synthesize CNPs [30, 35, 70-79].

\section{Sonochemical method}

In the sonochemical method, the reaction is done via the application of high-intensity ultrasound wave which forms acoustic cavitation, i.e., formation, growth and collapse of bubbles, resulting in the creation of very high local temperature and pressure that initiate a chemical reaction. These reactions are swift, and no external activation energy

\section{Table 4 Synthesis of nanoceria by oxidation method}

\begin{tabular}{|c|c|c|c|c|}
\hline S. no & Precursors & Medium & Method & References \\
\hline 1. & Cerium nitrate hexahydrate, hydrogen peroxide, and ammonia solution & Water & Hydrothermal oxidation method & [69] \\
\hline 2. & Cerium nitrate hexahydrate, ammonia solution, and hydrogen peroxide & Water & Oxidation method & {$[30]$} \\
\hline 3. & Cerium sulfate, sodium hydroxide, and hydrogen peroxide & Water & Sonochemical oxidation & {$[72]$} \\
\hline 4. & Cerium nitrate hexahydrate and hydrogen peroxide & Water & Oxidation & {$[11,73-75]$} \\
\hline 5. & Cerium nitrate, polyethylene glycol, and hydrogen peroxide & $\begin{array}{l}20 \% \text { polyethylene } \\
\text { glycol solution }\end{array}$ & Oxidation & {$[76]$} \\
\hline 6. & Cerium nitrate hexahydrate, dextran and ammonium hydroxide & Water & Oxidation & {$[35,77,78]$} \\
\hline 7. & Cerium nitrate hexahydrate, polyacrylic acid, and ammonium hydroxide & Water & Oxidation & {$[78]$} \\
\hline 8. & Cerium (III) acetate hydrate and hydrogen peroxide & Water & Precipitation method & {$[79]$} \\
\hline 9. & Cerium nitrate hexahydrate and hydrogen peroxide & Polyethylene glycol & Oxidation & {$[70]$} \\
\hline 10. & $\begin{array}{l}\text { Cerium nitrate hexahydrate, hydrogen peroxide, and ammonium hydrox- } \\
\text { ide }\end{array}$ & Dextran & Oxidation & {$[71]$} \\
\hline
\end{tabular}

Table 5 Synthesis of nanoceria by sonochemical method

\begin{tabular}{|c|c|c|c|c|}
\hline S. no & Precursors & Medium & Method & References \\
\hline 1. & Cerium nitrate and azodicarbonamide & Water & Sonochemical synthesis & {$[81]$} \\
\hline 2. & Ammonium cerium nitrate, hexamethylenetetramine, and polyethylene glycol & Water & Sonochemical method & {$[82]$} \\
\hline 3. & Cerium nitrate hexahydrate, tetra ethylene glycol, and ammonium hydroxide & Water & Sonochemical method & {$[83]$} \\
\hline 4. & Cerium nitrate hexahydrate, CTAB surfactant, and ammonia solution & Water & Ultrasonication & {$[84]$} \\
\hline 5. & Cerium nitrate hexahydrate and aqueous ammonia solution & Water & Sonochemical hydrolysis method & {$[85]$} \\
\hline
\end{tabular}


and pressure are applied [80]. Several researchers used this method to synthesize CNPs, as mentioned in Table 5.

The first sonochemical synthesis of nanoceria was reported in 2002 by Yin et al. [81] and Wang et al. [82]. Yin et al. [81] synthesized nanoceria using cerium nitrate and azodicarbonamide as precursors, while ethylenediamine or tetraalkylammonium hydroxide as additives. Those additives showed a potent effect on the size of nanoparticles. They observed that the addition of additives reduced the particle size, whereas, in the absence of additives, agglomerated nanoceria was obtained. On the other hand, Wang et al. [82] used ammonium cerium nitrate and hexamethylenetetramine as precursors for nanoceria synthesis.

Dutta et al. [83] synthesized flower-like nanoceria from cerium nitrate hexahydrate, tetraethylene glycol, and ammonium hydroxide. Later, several other researchers also synthesized nanoceria by a sonochemical method using cerium nitrate hexahydrate $[84,85]$.

\section{Microwave assisted method}

The microwave-assisted method has been considered as one of the most sustainable methods for the synthesis of nanoceria. It is more efficient than any other conventional heating method because the microwaves couple directly with the solvent and reactant molecules present in the reaction mixture due to which the energy transfer takes place quickly leading to a rapid rise in the temperature of the system [86]. In this method, the reaction is completed within a short time, and spotless products are obtained with a higher yield [87]. Several researchers used this method for the preparation of nanoceria, as described in Table 6.

Wang et al. [82] first synthesized nanoceria by microwave-assisted heating methods from ammonium cerium nitrate, hexamethylenetetramine and polyethylene glycol as precursors. A microwave oven with $650 \mathrm{~W}$ power was used in this method. The as-prepared nanoceria was spherical having an average diameter in the range of 2-3 nm.

Later, Gao et al. [88] synthesized cerium oxide nanoparticles and nanorods by a microwave-assisted hydrothermal method from ammonium cerium nitrate and using different base additives such as sodium hydroxide, ammonia water, urea, ethylene diamine, and formamide. The nanoceria prepared with different base additives possessed particle-like morphology but have different particle size. However, as prepared nanoparticles showed different morphologies when the cerium source was changed to cerium chloride and using a different quantity of ammonia water. Some other researchers also synthesized nanoceria by this method [89-91].

\section{Combustion method}

Combustion method is also known as self-propagating high-temperature synthesis (SHS), which is a simple, rapid, and effective technique to prepare various nanoparticles. On the basis of the physical nature of initial reaction medium used, this method is further classified as, condensed phase combustion or Conventional SHS (in which the initial reaction medium is in solid state), solution-combustion synthesis (in which the initial

Table 6 Synthesis of nanoceria by microwave-assisted method

\begin{tabular}{|c|c|c|c|c|}
\hline S. no & Precursors & Medium & Method & References \\
\hline 1. & $\begin{array}{l}\text { Ammonium cerium nitrate, hexamethylenetetramine, and polyethylene } \\
\text { glycol }\end{array}$ & Water & Microwave-assisted heating & {$[82]$} \\
\hline 2. & Ammonium cerium nitrate and sodium hydroxide & Water & Microwave-assisted hydrothermal method & {$[88]$} \\
\hline 3. & $\begin{array}{l}\text { Cerium nitrate hexahydrate, ethylene glycol, oleic acid, and tert-butyl- } \\
\text { amine }\end{array}$ & Water & Microwave-assisted method & [89] \\
\hline 4. & Cerium nitrate hexahydrate, propylene glycol, and ammonia & Water & Microwave technique & {$[90]$} \\
\hline 5. & Ceric ammonium nitrate and sodium hydroxide & Water & Microwave-mediated synthesis & [91] \\
\hline
\end{tabular}

Table 7 Synthesis of nanoceria by combustion method

\begin{tabular}{|c|c|c|c|c|}
\hline S. no & Precursors & Medium & Method & References \\
\hline 1. & Cerium nitrate hexahydrate, europium nitrate, and urea & Water & Solution combustion synthesis & [93] \\
\hline 2. & Cerium nitrate, rare earth nitrate, and anhydrous citric acid & Water & Combustion method & [94] \\
\hline 3. & Cerium nitrate hexahydrate, $\mathrm{Sm}\left(\mathrm{NO}_{3}\right)_{3}$, urea and PVA & Water & Combustion method & {$[95]$} \\
\hline 4. & Ceric ammonium nitrate and EDTA disodium salt & Water & Solution combustion method & [96] \\
\hline
\end{tabular}


reactants are in aqueous state) and gas phase combustion (in which nanoparticles are synthesized in flame) [92]. Synthesis of nanoceria by this method has been summarized in Table 7.

Shi et al. [93] reported the synthesis of europiumdoped nanoceria by solution combustion synthesis approach for the first time. They used cerium nitrate hexahydrate, europium nitrate, and urea as precursors, and the as-prepared nanoceria had an average size of $60 \mathrm{~nm}$ with photoluminescence and X-ray luminescence properties.

Later, Jamshidijam et al. [94] used combustion method to synthesize rare nanocrystalline earth-doped ceria nano-powders. They used a mixture of rare earth (RE) nitrates containing cerium and anhydrous citric acid. The size of the synthesized nanoceria was found to be $17-19.5 \mathrm{~nm}$ by using Scherrer's formula. In the same year, Wu et al. [95] also synthesized nanoceria by a combustion method, using cerium nitrate hexahydrate, $\mathrm{Sm}\left(\mathrm{NO}_{3}\right)_{3}$, urea, and PVA as raw materials.

Ravishankar et al. [96] prepared nanoceria from ceric ammonium nitrate and EDTA disodium salt as precursors. The synthesized nanoceria was spherical with the average size of $42 \mathrm{~nm}$ and exhibited photocatalytic as well as antibacterial activity.

\section{Micro-emulsion method}

Micro-emulsions are colloidal solutions having two immiscible solvents (water and oil), a surfactant and a co-surfactant. They can be prepared rapidly by stirring the above-mentioned components, and the formed microemulsions are thermodynamically stable solutions [97]. Microemulsions are of different types such as oilin-water $(\mathrm{O} / \mathrm{W})$ microemulsions, water-in-oil $(\mathrm{W} / \mathrm{O})$ microemulsions, bicontinuous microemulsions, and supercritical $\mathrm{CO}_{2}$ microemulsions [98]. Micro-emulsion method has been adopted by several researchers for the synthesis of nanoceria as illustrated in Table 8 .

Patil et al. [99] and Das et al. [100] used this method to obtain nanoceria using cerium nitrate hexahydrate and ammonium hydroxide as precursors, bis (2-ethylhexyl) sulphosuccinate as a surfactant, and toluene and water as solvents. The formed nanoceria was monodispersed, having a size in the range of $5 \mathrm{~nm}$ with a spherical shape.

Sathyamurthy et al. [101] reported the synthesis of nanoceria by reverse micellar method or water in oil microemulsion method. They used the same precursor molecule, but different surfactant, such as cetyltrimethylammonium bromide and 1-butanol as a co-surfactant. Water and $n$-octane were used as aqueous and oil phase, respectively. The as-synthesized nanoceria had a polyhedral shape with the average size of about $3.7 \mathrm{~nm}$ and was found to exhibit room temperature photoluminescence and strong UV absorption.

Huang et al. [102] reported nanoceria synthesis via a similar method, where the same precursor molecule and solvent systems are used, but with a different surfactant, polyvinyl pyrrolidone (PVP). They synthesized nanoceria with different morphologies by controlling the $\mathrm{pH}$ of the solution. As the $\mathrm{pH}$ value increased from 5 to 8 to 11 , the morphology of nanoceria transferred from granular to spherical and then to rod-like.

Tiseanu et al. [103], synthesized nanoceria via oilin-water microemulsion method. They synthesized pure and europium doped nanoceria from Cerium (III) 2-ethyl hexanoate and europium (III) 2-ethyl hexanoate as precursors, hexaethylene glycol isodecyl ether as a surfactant, hexane solution as oil phase and water. The obtained nanoparticles possessed a very high surface area of $\sim 250 \mathrm{~m}^{2} / \mathrm{g}$ having a size of about $3 \mathrm{~nm}$.

\section{Sol-gel method}

This method involves a few steps, such as hydrolysis, condensation, and drying, to form a final nanoparticle. Depending upon the type of solvent used, this method is further classified into two classes-aqueous sol-gel method (water is used as solvent) and non-aqueous solgel method (organic solvent is used). Nature of metal precursor and solvent plays a significant role in this method to synthesize metal oxide nanoparticles [104]. The

\section{Table 8 Synthesis of nanoceria by a microemulsion method}

\begin{tabular}{|c|c|c|c|c|}
\hline S. no & Precursors & Medium & Method & References \\
\hline 1. & $\begin{array}{l}\text { Cerium nitrate hexahydrate, ammonium hydroxide and bis (2-ethylhexyl) } \\
\text { sulphosuccinate }\end{array}$ & Toluene and water & Microemulsion method & {$[99,100]$} \\
\hline 2. & $\begin{array}{l}\text { Cerium nitrate hexahydrate sodium hydroxide and cetyl trimethyl ammonium } \\
\text { bromide }\end{array}$ & Water and n-octane & $\begin{array}{l}\text { Reverse micellar method } \\
\text { or water in oil micro- } \\
\text { emulsion }\end{array}$ & {$[101]$} \\
\hline 3. & $\begin{array}{l}\text { Cerium nitrate hexahydrate, ammonium hydroxide, polyvinylpyrrolidone and } \\
\text { butanol }\end{array}$ & Water and n-octane & Microemulsion method & {$[102]$} \\
\hline 4. & Cerium(III) 2-ethylhexanoate, ammonia, and hexaethylene glycol isodecyl ether & Water and hexane & Oil in water microemulsion & {$[103]$} \\
\hline
\end{tabular}


Table 9 Synthesis of nanoceria by Sol-gel method

\begin{tabular}{|c|c|c|c|c|}
\hline S. no & Precursors & Medium & Method & References \\
\hline 1. & Cerium nitrate hexahydrate and oleic acid & $\begin{array}{l}\text { Tri-n-octylamine, oleyamine and } \\
\text { diphenyl ether }\end{array}$ & $\begin{array}{l}\text { Nonhydrolytic sol- } \\
\text { gel method }\end{array}$ & [105] \\
\hline 2. & $\begin{array}{l}\text { Cerium nitrate hexahydrate and europium nitrate pentahydrate } \\
\text { and citric acid monohydrate }\end{array}$ & Water and polyethylene glycol & Sol-gel method & [106] \\
\hline 3. & Cerium chloride heptahydrate and aqueous ammonia solution & Water and methanol & Sol-gel method & [107] \\
\hline
\end{tabular}

sol-gel method is a considerable approach to synthesize nanoceria, as depicted in Table 9.

Non-hydrolytic sol-gel method has been used by $\mathrm{Yu}$ et al. [105], to synthesize nanoceria from cerium nitrate hexahydrate and diphenyl ether in oleylamine. The CNPs thus obtained were spherical having $3.5 \mathrm{~nm}$ in size. They also reported that anisotropic wire and tadpole-shaped nanoceria were obtained if oleic acid (cosurfactant) was added to the solution in addition to oleylamine.

Li et al. [106] prepared undoped and europium doped nanoceria by using the sol-gel method. They used cerium and europium nitrate as the starting materials, and water and polyethylene glycol as solvents. They reported the photoluminescence properties of the europium-doped nanoceria at different europium doping concentrations and different temperatures. In 2011, Gnanam et al. [107] also prepared CNPs from cerium chloride heptahydrate and aqueous ammonia solution as precursors, water, and methanol as solvents.

\section{Other methods}

Besides the above discussed conventional methods, some researchers have also reported other methods for the preparation of nanoceria, as shown in Table 10. Some of these methods are:

- Non-hydrolytic solvent method Wang et al. [108] used this method for the preparation of nanoceria using cerium acetate hydrate, oleyamine, oleic acid, and $\mathrm{NaOH}$ as precursors in hexadecane medium. The as-prepared nanoceria had an average size of $3.5 \mathrm{~nm}$ with a cubic structure.
- Direct room temperature and solvothermal method Kar et al. [109] synthesized ultra-small cerium oxide nanoparticles having size $2.5 \pm 0.2 \mathrm{~nm}$ from cerium nitrate hexahydrate and ethylene diamine by this method.

- Aqueous phase synthesis Yu et al. [110] reported the synthesis of ultrathin cerium oxide nanosheets by this method, using cerium nitrate hexahydrate and 6-aminohexanoic acid (AHA) as starting materials.

- Partial oxidation method This method was used to synthesize nanoceria by Lan et al. [111] using cerium carbonate hydrate in a molten $\mathrm{KOH}-\mathrm{NaOH}$ mixture. They observed that with the increase in the synthesis temperature, the size of the synthesized nanoceria was also increased.

- Solution plasma process The solution plasma process is a new, fast, and efficient method for the preparation of nanoparticles. This is an electrical discharge process, which takes place in a wet environment, generally at room temperature and an atmospheric non-equilibrium plasma is produced [112]. The advantage of this method is that it can be carried out at ambient temperature and pressure without the addition of any harmful chemicals [113]. Davoodbasha et al. [114] reported the synthesis of nanoceria by discharging plasma in a cerium nitrate solution. The synthesized nanoceria was spherical and possessed an average size of $7.0 \pm 0.2 \mathrm{~nm}$ and $5.0 \pm 0.2$ when the sample had been discharged with plasma for $15 \mathrm{~min}$ and 25 min respectively. The obtained nanoceria showed excellent antioxidant properties.

Table 10 Synthesis of nanoceria by other methods

\begin{tabular}{|c|c|c|c|c|}
\hline S. no & Precursors & Medium & Method & References \\
\hline 1. & Cerium acetate hydrate, oleyamine, oleic acid, and $\mathrm{NaOH}$ & Hexadecane & Nonhydrolytic solvent method & {$[108]$} \\
\hline 2. & Cerium nitrate hexahydrate and ethylene diamine & $\begin{array}{l}\text { Ethylenediamine } \\
\text { and water }\end{array}$ & $\begin{array}{l}\text { Direct room temperature and } \\
\text { solvothermal method }\end{array}$ & {$[109]$} \\
\hline 3. & Cerium nitrate hexahydrate and 6-aminohexanoic acid (AHA) & Water & Aqueous phase synthesis & {$[110]$} \\
\hline 4. & Cerium carbonate hydrate, and Molten $\mathrm{KOH}-\mathrm{NaOH}$ mixture & Nil & Partial oxidation method & {$[111]$} \\
\hline 5. & Cerium nitrate & Water & Solution plasma process & {$[114]$} \\
\hline
\end{tabular}




\section{Functionalization and loading of nanoceria with different ligands or drugs}

Nanoceria has been functionalized with various ligands and loaded with drugs for targeted and effective drug delivery into cancer cells. Several researchers have used different functionalization or loading methods for different ligands and drugs. Patil et al. [115] functionalized nanoceria with carboxybenzenesulfonamide (a human carbonic anhydrase inhibitor) and carboxyfluorescein (a fluorophore) molecules via simple condensation reactions using epichlorohydrin as a linker molecule.

In 2017, Das et al. [116] loaded doxorubicin (a chemotherapeutic drug) on nanoceria by electrostatic interactions between negatively charged nanoceria and positively charged doxorubicin at $\mathrm{pH}$ 7.0.

Later in 2017, Sulthana et al. [33] reported the functionalization of nanoceria with polyacrylic acid (PAA) by simple alkaline precipitation of cerium ions in the presence of PAA. PAA coated nanoceria were further conjugated with propergylamine via amide bond formation, and the as-synthesized propergylated nanoceria was further conjugated with folic acid using "Click" chemistry. Finally, two drugs, namely ganetespib (an Hsp 90 inhibitor) and doxorubicin, were loaded onto the nanoceria via solvent diffusion method.
Kalashnikova et al. [34] prepared dextran functionalized nanoceria by simple alkaline precipitation of cerium ions in the presence of dextran. The as-prepared nanoceria was then further loaded with curcumin via metal-ligand chelation.

Zhang et al. [52] first prepared porous cerium oxide nanorods and then loaded doxorubicin inside the pores. After that, they coated the drug-loaded pores by a dithio-polydopamine layer by self-polymerization. Finally, the amine functionalized lactoses were conjugated on the polydopamine surface via a Michael addition reaction.

\section{Biomedical applications of nanoceria}

Nanoceria has emerged as one of the vital metal oxide nanoparticles due to its wide range of applications in different fields, particularly in biomedicine. Here we have discussed its various biomedical applications.

\section{Antibacterial activity}

Nanoceria has been known to possess profound antibacterial activity against both Gram-positive and Gramnegative bacteria. There are two mechanisms by which nanoceria cause bacterial cell death; namely direct and indirect contact mechanisms (Fig. 2). In direct contact,

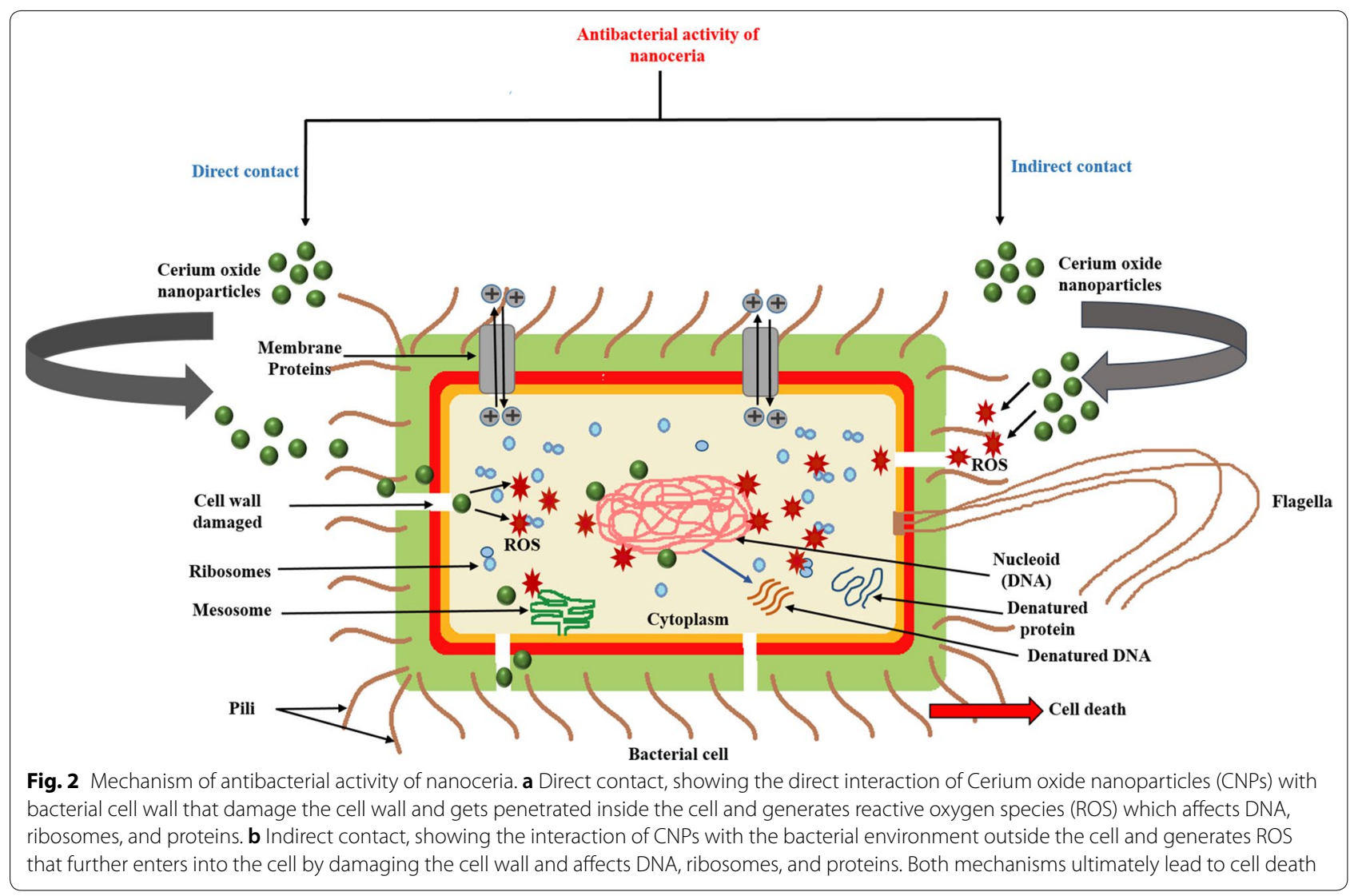


nanoceria gets directly adsorbed on the bacterial cell and damage the outer cell wall that further leads to the generation of intracellular ROS [117]. Arumugam et al. [58] demonstrated that positively charged nanoceria gets well adsorbed on the bacterial cell due to the electrostatic interaction. Due to this interaction, the cellular proteins become inactive, and nanoceria gets penetrated inside the bacterial cell and deactivating the bacterial enzymes, which generate hydrogen peroxide (ROS). The intracellular ROS so generated further damages DNA, RNA, and protein, which ultimately caused bacterial cell death [59]. Besides, Thill et al. [118] demonstrated that nanoceria might undergo reduction from $\mathrm{Ce}^{4+}$ to $\mathrm{Ce}^{3+}$ on the cell surface upon adsorption via oxidation of the bacterial wall membrane, thereby leading to oxidative stress.

While in the indirect contact, nanoceria interacts with the environment (intercellular space) around the bacteria and the products (maybe extracellular ROS) formed by this interaction further damage the bacterial cells. This indirect interaction mechanism generally occurs in polysaccharide encapsulated bacteria (the bacteria which have polysaccharide layer around the cell envelope), where nanoparticles have no direct contact with the cell wall. So, in this type of interaction, ROS are generated outside the bacterial cell which enters into the cell through the cell membrane and damages the bacterial cells by degrading nucleic acids and protein which ultimately leads to cell death [117]. Oxygenic photosynthesis is one of the sources of ROS production in cyanobacteria. The ROS which is generated by this process react with $\mathrm{Ce}^{3+}$ site at the surface of CNP (which is in close contact with cyanobacteria) and further undergoes oxidative reaction and generates superoxide anions and hydroxyl radicals. These ROS further affect the photosynthetic process and impair membrane integrity by lipid peroxidation, which further leads to cell death [119].

However, in healthy human cells, nanoceria acts as an antioxidant by scavenging ROS. This is due to their ability to show superoxide dismutase (SOD) mimetic activity and catalase (CAT) mimetic activity. For nanoceria, a higher $\mathrm{Ce}^{3+} / \mathrm{Ce}^{4+}$ ratio is necessary for SOD-mimetic activity, whereas for CAT mimetic activity, a higher $\mathrm{Ce}^{4+}$ / $\mathrm{Ce}^{3+}$ ratio is necessary. As nanoceria is capable of interconverting its +4 and +3 oxidation states, it is capable of neutralizing both superoxide and hydrogen peroxide on demand [25]. However, in cancer cells, there is acidic $\mathrm{pH}$ which promotes SOD mimetic activity of CNPs but inhibits its catalase mimetic activity which results in the accumulation of the huge amount of $\mathrm{H}_{2} \mathrm{O}_{2}$ (ROS) in the cancer cell. So in cancer cells, CNPs showed toxic effects by producing ROS [120]. However, the antibacterial properties of nanoceria depend upon some crucial factors, such as size [121], concentration [58], $\mathrm{pH}$ [122], surface coating [123] and surface chemistry [124]. Several researchers studied the antibacterial activity of nanoceria against different strains of bacteria, as mentioned in Table 11.

In 2006, Thill et al. [118] studied the antibacterial activity of positive charged ellipsoidal nanoceria with $7 \mathrm{~nm}$ size within the concentration range between 1 and $730 \mathrm{mg} / \mathrm{L}$ against $E$. coli (Gram-negative bacteria). They observed that a large amount of nanoceria was adsorbed on the outer membrane of $E$. coli by direct contact, which further results in bacterial cytotoxicity. Similar kind of antibacterial activity of nanoceria against $E$. coli has also been reported by other researchers [121, 123, 125-128].

Later, Kannan et al. [59] reported the antibacterial activity of nanoceria $(25-30 \mathrm{~nm}$ ) against E. coli (Gram negative) and Staphylococcus aureus (Gram positive) bacteria. They observed that nanoceria inhibited the growth of those bacteria by more than $90 \%$. Unnithan et al. [129] assessed the effects of nanoceria doped composite nanofibres on different types of pathogenic bacteria, such as E. coli (Gram negative), K. pneumonia (Gram negative), S. enterica (Gram negative), S. aureus (Gram positive) and E. faecalis (Gram positive). They observed that the number of bacterial colonies was decreased with increasing nanoceria concentrations from 50 to $500 \mathrm{mg} /$ $\mathrm{mL}$. They also found that nanoceria caused disintegration of the bacterial cell membrane, which further resulted in cell death. Later in 2015, Arumugam et al. [58] demonstrated a dose-dependent antibacterial activity of green synthesized nanoceria against different Gram-positive (Staphylococcus aureus, Streptococcus pneumonia) and Gram-negative bacteria (Escherichia coli, Proteus vulgaris, Pseudomonas aeruginosa, Klebsiella pneumonia, and Shigella dysenteriae).

After that Reshma and Ashwini [130] studied the antibacterial activity of nanoceria against several Gram-positive (Corynebacterium diphtheria and Sarcinalutea) and Gram-negative (Escherichia coli and Proteus vulgaris) bacteria and showed a significant antibacterial effect of nanoceria. Besides, nanoceria also showed a zone of inhibition for the Gram-negative bacteria.

In the same year, Alpaslan et al. [122] examined the $\mathrm{pH}$, concentration and time-dependent antibacterial activity of dextran-coated nanoceria against Pseudomonas aeruginosa (Gram negative bacteria) and Staphylococcus epidermidis (Gram-positive bacteria). They observed that nanoceria showed excellent antibacterial activity against both the bacteria at basic $\mathrm{pH}(\mathrm{pH}=9)$ compared to acidic $\mathrm{pH}$ value $(\mathrm{pH}=6)$ due to positive surface charge and smaller sufficient size. They also found that at $\mathrm{pH} 9, S$. epidermidis did not grow at all when treated for $24 \mathrm{~h}$ with $500 \mu \mathrm{g} / \mathrm{mL}$ nanoceria, whereas $P$. aeruginosa has grown 


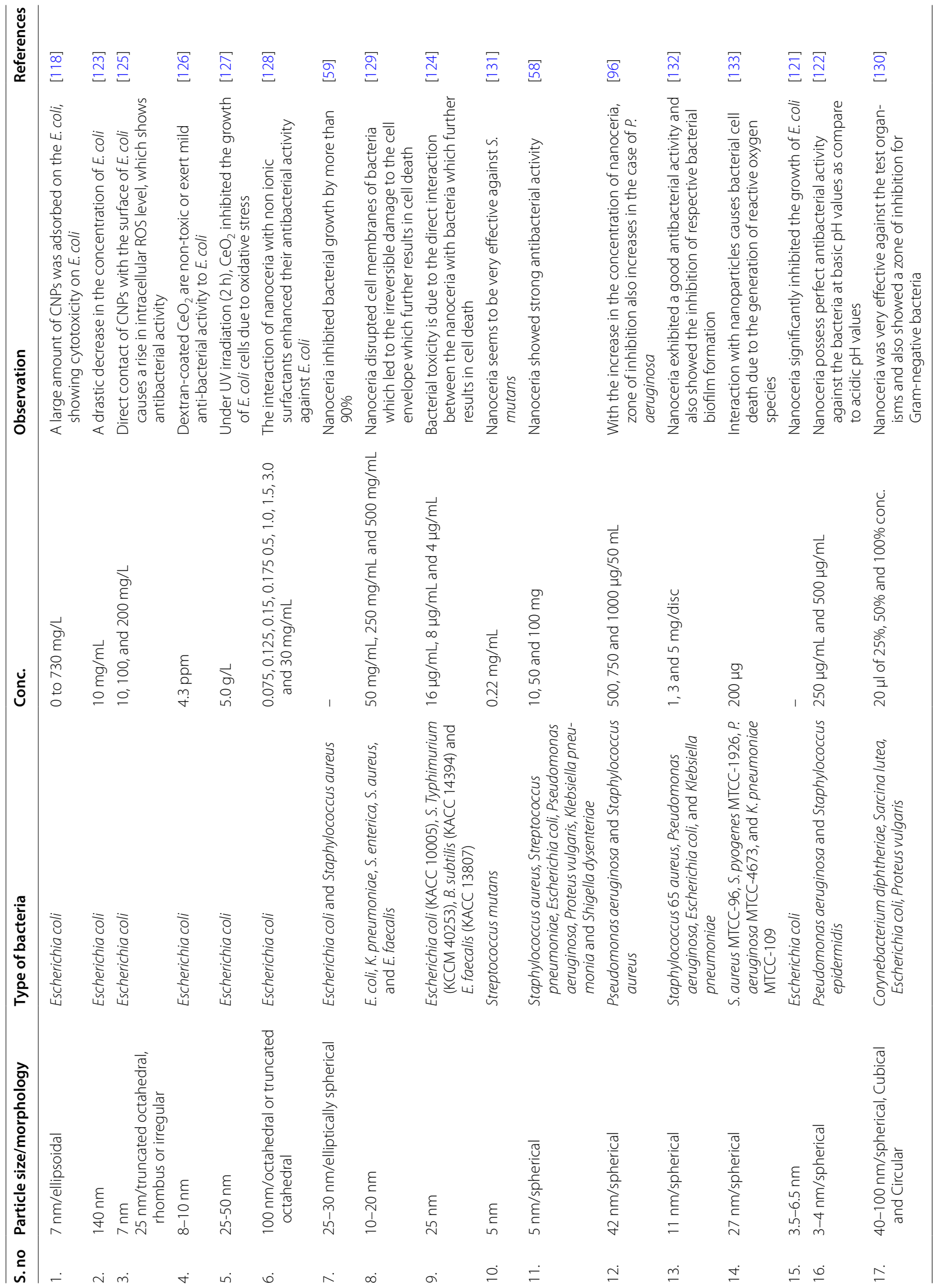


very slowly at different particle concentrations $(250 \mu \mathrm{g} /$ $\mathrm{mL}$ and $500 \mu \mathrm{g} / \mathrm{mL}$ ).

Some other researchers [96, 131-133] have also reported the antibacterial activity of nanoceria against different strains of bacteria.

\section{Antioxidant activity}

Nanoceria seems to exhibit vigorous antioxidant activity due to its ability to switch between two oxidation states, $\mathrm{Ce}^{3+}$ and $\mathrm{Ce}^{4+}$ depending on the environment. This unique redox property of nanoceria can protect different tissues and organs from cellular damage caused by various free radicals or reactive oxygen species (ROS) [76]. The mechanism of the antioxidant activity of nanoceria is shown in Figs. 3 and 4. This antioxidant activity of nanoceria has been examined by different researchers on different cell types, as mentioned in Table 12. In 2007, Das et al. [100] studied the antioxidant activity of nanoceria $(3-5 \mathrm{~nm})$ in a serum-free cell culture model of adult rat spinal cord. They observed higher cell survival and less cell death after both 15 and 30 days of culture with medium containing nanoceria as compared to the untreated control cultures. These results showed that nanoceria acts as an antioxidant that scavenges various free radicals present in the culture medium and provides neuroprotection to adult rat spinal cord neurons.

Later, Colon et al. [134] studied the radioprotective effect of nanoceria against gastrointestinal epithelium. In their work, they pretreated human colon cells (CRL 1541) with different concentration of nanoceria for $24 \mathrm{~h}$ before radiation exposure. They demonstrated that nanoceria acts as a free radical scavenger and protects the human colon cells from radiation-induced oxidative damage via increased cellular production of superoxide dismutase 2 .

In 2013, Chen et al. [135] reported the antioxidant activity of nanoceria $(20 \mathrm{~nm})$ in endothelial cells against $\mathrm{H}_{2} \mathrm{O}_{2}$. They treated the cultured endothelial cells with different conc. $(5,10,20$, and $40 \mu \mathrm{g} / \mathrm{mL})$ of nanoceria for 6 to $48 \mathrm{~h}$, and found that the nanoparticles were up taken into the cells through caveolae- and clathrin-mediated endocytosis. After being internalized into endothelial cells, nanoceria effectively counteracts the overproduction of ROS by $\mathrm{H}_{2} \mathrm{O}_{2}$ and decrease the percentage of apoptotic cell death. Based on their observations, they predicted that nanoceria might help in preventing cardiovascular diseases which are caused by oxidative insult. Rubio et al. [136] studied the antioxidant activity of nanoceria in a pulmonary-like cell system against $\mathrm{KBrO}_{3}$-induced oxidative stress. They used a human epithelial lung cell line, BEAS-2B, and pretreated those cells with nanoceria before $\mathrm{KBrO}_{3}$ exposure. They showed that nanoceria reduced the intracellular ROS production and thus prevented cell death. Kim et al. [137] analyzed the antioxidant activity of levan coated nanoceria in NIH3T3 cells against $\mathrm{H}_{2} \mathrm{O}_{2}$. Levan and their derivatives are well known for their antioxidant, anti-tumor and anti-inflammation properties, and levan coating also confer stability and water solubility to nanoceria. They demonstrated that conjugation of levan with nanoceria exert a synergistic antioxidant effect against $\mathrm{H}_{2} \mathrm{O}_{2}$ stimulated NIH3T3 cells.

Recently, Ranjbar et al. [138] used brain tissue samples of rats to examine the antioxidant activity of nanoceria against paraquat $(\mathrm{PQ})$ induced brain injury. They observed that nanoceria enhanced the antioxidant defense mechanism via increasing the total thiol content and total antioxidant capacity, thereby decreased the lipid peroxidation, oxidative DNA damage as well as caspase 3 activity. Besides, the mRNA levels of Nestin and Neurod1 has also been increased in the brain samples upon nanoceria treatment. Therefore, nanoceria possessed antioxidant and neuroprotective effect against paraquat-induced neuronal oxidative stress and apoptosis in vivo. The antioxidant activity of nanoceria has also been reported by several other researchers [35, 139-141].

\section{Anticancer activity}

In addition to the antibacterial and antioxidant activity, nanoceria is also known to exhibit profound anticancer potential. It provides cytoprotection towards healthy cells from ROS but kills cancer cells via inducing ROS formation. The mechanism of the anticancer activity of nanoceria is depicted in Fig. 4. Cancer cells have a higher acidic environment compared to healthy cells due to an increased rate of glycolysis and lactic acid production [35]. In the acidic environment (low $\mathrm{pH}$ ), the antioxidant (cytoprotective) activity of nanoceria is lost, and it acts as a prooxidant which causes oxidative stress by producing ROS and thus induces cell death/apoptosis [25]. This activity of nanoceria has been studied by many researchers against different cancer cell lines, as illustrated in Table 13.

In 2006, Lin et al. [142] studied the anticancer effect of nanoceria $(20 \mathrm{~nm})$ in human lung cancer cells (A549 cells), which were exposed to different conc. $(3.5,10.5$, and $23.3 \mu \mathrm{g} / \mathrm{mL}$ ) of nanoceria for 24,48 , and $72 \mathrm{~h}$. They showed a dose and time-dependent cytotoxicity of nanoceria towards A59 cells via oxidative stress. Renu et al. [48] demonstrated that nanoceria with conc. Of $5 \mathrm{mg} / \mathrm{mL}$ showed cytotoxicity towards prostate cancer cell line (PC3), but nontoxic towards normal mouse fibroblast cell line (L929). They prepared nanoceria by two different methods; hydrolysis (HL) method resulted in the formation of nanoceria with +3 oxidation state and hydrothermal (HT) method resulted in the formation of nanoceria with +4 oxidation state. They also observed 


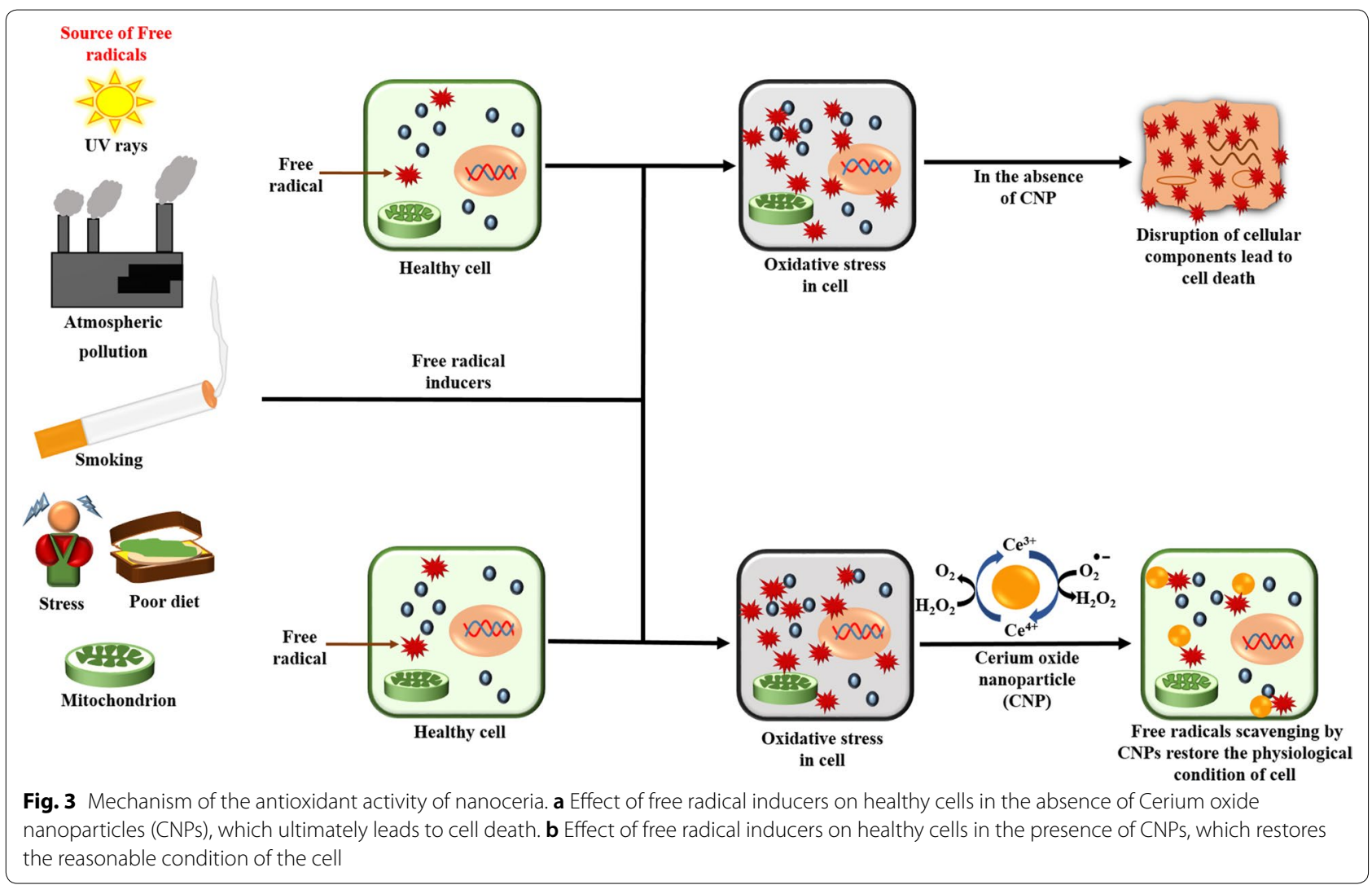

that HT-nanoceria were more cytotoxic towards PC3 cells compared to HL-nanoceria because of their increased cellular uptake. In 2013, Giri et al. [75] studied the anticancer effects of nanoceria in ovarian cancer cells (A2780) and A2780 xenograft tumor mice model. They treated the A2780 xenograft mice with $0.1 \mathrm{mg} / \mathrm{kg}$ body weight of nanoceria intra-peritoneally every third day till up to 30 days and compared the tumor growth with the untreated mice. They observed that the tumor weight and the abdominal circumference in the mice treated with nanoceria were significantly reduced as compared to the untreated mice. They showed that nanoceria had a tendency to inhibit metastasis and angiogenesis in ovarian cancer cells and thus attenuated ovarian tumor growth. Hijaz et al. [143] also demonstrated that folic acid tagged nanoceria possessed significant anticancer activity against ovarian cancer cells (A2780) and A2780-xenograft tumor mice. In their in vivo experiment, they treated A2780 xenografts tumor mice with $0.1 \mathrm{mg} / \mathrm{kg}$ body weight of either bare nanoceria or folic acid tagged nanoceria. They observed that folic acid tagged nanoceria was more effective in restricting the tumor growth in mice via targeted delivery into tumor cells.

Cytotoxic effects of nanoceria in human colon cancer cells (HCT 15) were observed in a dose- and time-dependent manner by Jana et al. [144]. They showed that the exposure of nanoceria with conc. between 10and $100 \mu \mathrm{M}$ (for 24,48 and $72 \mathrm{~h}$ ) resulted in cytotoxicity via the production of ROS which subsequently depolarised the mitochondrial membrane and initiated apoptosis. Kumari et al. [145] checked the cytotoxic and genotoxic effects of both cerium oxide nanoparticles (CNPs) and cerium oxide microparticles (CMPs) in the human neuroblastoma cell line (IMR32) upon treatment with different conc. (100 and $200 \mu \mathrm{g} / \mathrm{mL}$ ) for $24 \mathrm{~h}$. They observed that the cells incubated with CNPs showed much higher production of intracellular ROS and induced higher cytotoxicity because of increased cellular uptake as compared to CMPs. Recently, in 2018, Nourmohammadi et al. [146] studied the anticancer activity of nanoceria against fibrosarcoma cell line (WEHI164), which showed dose-dependent cytotoxicity of nanoceria. They observed that nanoceria exposure with conc. $\geq 15.63 \mu \mathrm{g} / \mathrm{mL}$ showed profound cytotoxicity in cancer cells (WEHI164), whereas very little toxicity was observed in normal (L929) cells even at conc. above $250 \mu \mathrm{g} / \mathrm{mL}$. They further demonstrated that nanoceria exhibit toxicity in cancer cells by generating ROS which induces apoptotic cell death. 


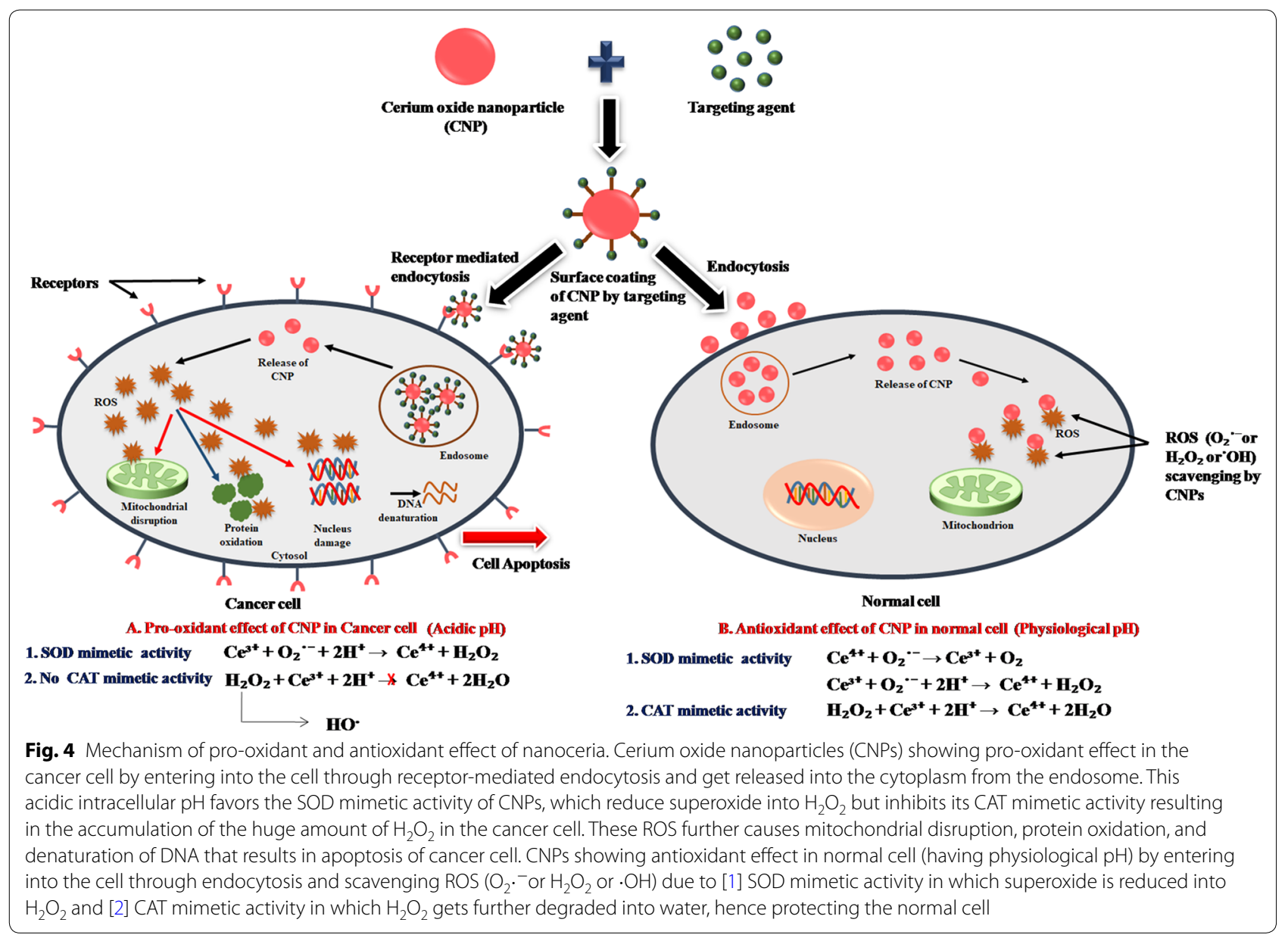

\section{Drug/gene delivery}

Recently, nanoceria has widely been used in the biomedical field as an effective and targeted drug and gene delivery vehicle. This drug-delivery application of nanoceria in cancer cells shows a synergistic anticancer effect due to its inherent cytotoxicity towards cancer cells (Fig. 5). The use of nanoceria as a drug and gene delivery systems has been studied by some researchers, as mentioned in Tables 14 and 15.

In 2007, Patil et al. [115] studied the utility of nanoceria as a potential drug delivery device by attaching carboxybenzene sulfonamide (an inhibitor of the human carbonic anhydrase enzyme) along with a fluorophore (carboxyfluorescein) to nanoceria using epichlorohydrin as a linker molecule. They demonstrated that such conjugated nanoceria could be used for the inhibition of human carbonic anhydrase enzyme (hCAII), which is very useful in the treatment of glaucoma. Later, Muhammad et al. [147] developed a redox-responsive mesoporous silica nanoparticle (MSN) based camptothecin (an anticancer drug) delivery vehicle for active transport of drug into human pancreatic cancer cells (BxPC-3 cells). They further capped the pores of the drug-loaded MSN using nanoceria to inhibit the premature leakage of the drug. However, the nanoceria lids were dissolved upon exposure to antioxidant molecules, like vitamin-c and GSH, and triggered the redox-responsive drug release. They also observed that camptothecin loaded and nanoceria capped MSN exhibit dose and time-dependent cytotoxicity in BxPC-3 cells due to its active intracellular uptake, dissolution of nanoceria lid in highly reducing cellular environment and release of the encapsulated drug. Li et al. [148] reported a nanoceria mediated delivery system by conjugating a photosensitizer, chlorin e6 (Ce6) and folic acid (FA) on polyethylenimine-PEGylation ceria nanoparticles (PPCNPs) for targeted photodynamic therapy to treat drug-resistant human breast cancer cells, MCF-7/ADR and xenograft murine model. They observed that upon near-infrared (NIR) irradiation, PPCNPs-Ce6-FA generate ROS, which leads to a reduction in $P$-glycoprotein expression, lysosomal membrane permeabilization, and cytotoxicity towards drug-resistant breast cancer cells even at shallow doses. They further treated the mice with free Ce6, PPCNPs-Ce6 or PPCNPs-Ce6/FA intravenously 
Table 12 Antioxidant activity

\begin{tabular}{|c|c|c|c|c|}
\hline S. no & Particle size/morphology & Cell type & Observation & References \\
\hline 1. & $3-5 \mathrm{~nm}$ & Adult rat spinal cord cells & $\begin{array}{l}\text { A significant neuroprotective effect on adult rat } \\
\text { spinal cord neurons were observed }\end{array}$ & {$[100]$} \\
\hline 2. & $4 \mathrm{~nm}$ & Cardiomyocytes and human dermal fibroblasts & $\begin{array}{l}\text { Dextran-coated nanoceria protects healthy cells } \\
\text { against hydrogen peroxide-induced oxidative } \\
\text { stress }\end{array}$ & [35] \\
\hline 3. & $3-5 \mathrm{~nm}$ & Human colon cells (CRL 1541) & $\begin{array}{l}\text { Nanoceria reduce ROS levels and protect healthy } \\
\text { human colon cells from radiation-induced } \\
\text { damage }\end{array}$ & [134] \\
\hline 4. & $5-8 \mathrm{~nm}$ & Cardiac progenitor cells (CPCs) & Nanoceria controls the oxidative stress in CPCS & [139] \\
\hline 5. & $20 \mathrm{~nm} /$ cubic & Endothelial cells & $\begin{array}{l}\mathrm{CeO}_{2} \text { reduces intracellular free radicals in } \\
\text { endothelial cells and thus helps in controlling } \\
\text { cardiovascular diseases }\end{array}$ & [135] \\
\hline 6. & $5-80 \mathrm{~nm} /$ cubic & Neuron-like PC12 cells & $\begin{array}{l}\mathrm{CeO}_{2} \text { scavenged } \mathrm{ROS} \text { and exerted neuroprotec- } \\
\text { tion via regulating genes involved in cellular } \\
\text { defense }\end{array}$ & [140] \\
\hline 7. & $<25 \mathrm{~nm} /$ cubic and triangular & A human epithelial lung cell line, BEAS-2B & $\begin{array}{l}\text { Pre-treatment of } \mathrm{CeO}_{2} \text { significantly reduced the } \\
\text { intracellular production of ROS induced by } \\
\mathrm{KBrO}_{3}\end{array}$ & [136] \\
\hline 8. & $5 \mathrm{~nm} /$ spherical & $\mathrm{NIH} 3 \mathrm{~T} 3$ cells & $\begin{array}{l}\text { Levan coated } \mathrm{CeO}_{2} \text { protected } \mathrm{NIH} 3 \mathrm{~T} 3 \text { cells against } \\
\mathrm{H}_{2} \mathrm{O}_{2} \text {-induced oxidative stress }\end{array}$ & {$[137]$} \\
\hline 9. & $<5 \mathrm{~nm}$ & Neuron-like SH-SY5Y cells & $\begin{array}{l}\text { Showing beneficial effects in terms of neurite } \\
\text { development and alignment }\end{array}$ & [141] \\
\hline 10. & $30 \mathrm{~nm}$ & Brain tissue samples of rats & $\begin{array}{l}\mathrm{CeO}_{2} \text { protected against Paraquat-induced neu- } \\
\text { ronal oxidative stress and apoptosis }\end{array}$ & [138] \\
\hline
\end{tabular}

\section{Table 13 Anticancer activity}

\begin{tabular}{|c|c|c|c|c|}
\hline S. no & Size $(\mathrm{nm})$ & Cell line & Observation & References \\
\hline 1. & 20 & Human lung cancer cells (A549 cells) & $\begin{array}{l}\text { Free radicals were generated on the exposure of } 3.5 \text { to } \\
23.3 \mu \mathrm{g} / \mathrm{mL} \text { nanoceria which causes oxidative stress } \\
\text { and cytotoxic effect in the cancer cells }\end{array}$ & {$[142]$} \\
\hline 2. & $100-200$ & Human prostate cancer cell line (PC-3) & $\begin{array}{l}\text { Nanoceria showed cytotoxicity in prostate cancer cells } \\
\text { but was non-toxic in normal cells at the conc. of } 5 \mathrm{mg} / \\
\mathrm{mL}\end{array}$ & {$[48]$} \\
\hline 3. & $3-5$ & $\begin{array}{l}\text { Ovarian cancer cells (A2780) and A2780 xenograft murine } \\
\text { model }\end{array}$ & $\begin{array}{l}\text { Conc. between } 25 \text { and } 50 \mu \mathrm{M} \text { showed an anti-angiogenic } \\
\text { effect in ovarian cancer cells and reduced tumor size } \\
\text { in vivo }\end{array}$ & {$[75]$} \\
\hline 4. & $3-5$ & Human colon cancer cells (HCT 15) & $\begin{array}{l}\text { Conc. between } 10 \text { and } 100 \mu \mathrm{M} \text { resulted in a significant } \\
\text { reduction of cell viability via increasing ROS levels }\end{array}$ & {$[144]$} \\
\hline 5. & $<25$ & Human neuroblastoma cell line (IMR32) & $\begin{array}{l}\text { Nanoceria exposure generated ROS that induced oxida- } \\
\text { tive stress, which leads to cytotoxicity and genotoxicity } \\
\text { in IMR32 cells at higher conc. (>100 } \mu \mathrm{g} / \mathrm{mL})\end{array}$ & {$[145]$} \\
\hline 6. & 10 & $\begin{array}{l}\text { Ovarian cancer cells (A2780) and A2780 xenograft murine } \\
\text { model }\end{array}$ & $\begin{array}{l}\text { Folic acid tagged nanoceria showed significant inhibition } \\
\text { in viable cells in A2780 cells within the conc. range } \\
10-100 \mu \mathrm{M} \text {, and reduced tumor size in vivo }\end{array}$ & {$[143]$} \\
\hline 7. & 30 & Fibrosarcoma cell line (WEHI164) & $\begin{array}{l}\text { Conc. of nanoceria } \geq 15.63 \mu \mathrm{g} / \mathrm{mL} \text { showed toxicity effects } \\
\text { in cancer cells via increasing ROS levels and apoptosis }\end{array}$ & {$[146]$} \\
\hline
\end{tabular}

and irradiated with NIR at the tumor site. The mice treated with PPCNPs-Ce6/FA showed significant tumor growth inhibition in drug-resistant MCF-7/ADR tumors with a decrease in the $\sim 96 \%$ volume of the tumor via the production of ROS. On the other hand, the mice treated with PPCNPs-Ce6 or free Ce6 after irradiation showed weaker or no effect on tumor growth. However, without irradiation, the administration of PPCNPs-Ce6/FA showed no tumor regression in the mice. 


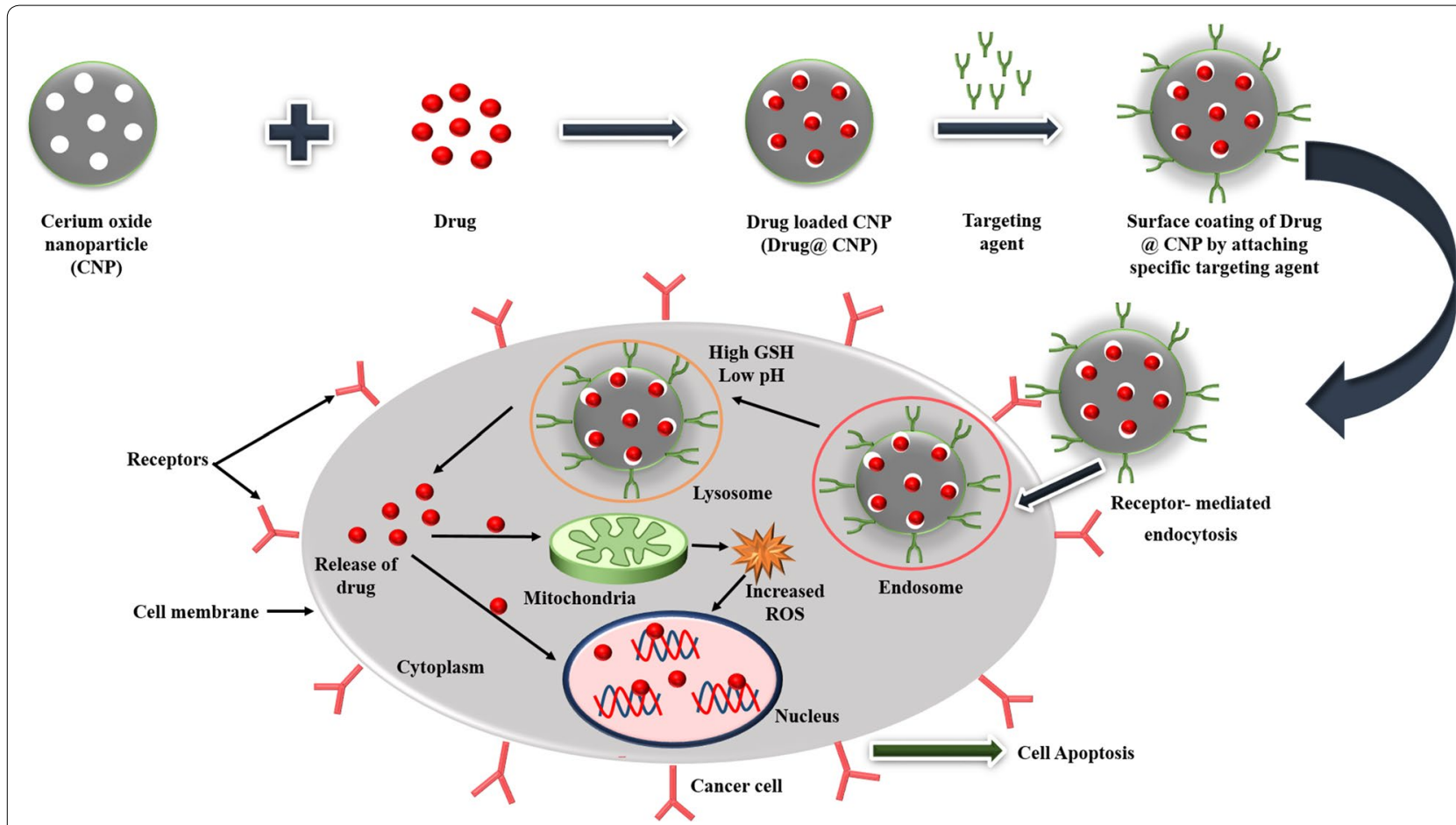

Fig. 5 Schematic diagram of drug delivery activity of nanoceria in the cancer cell. Drug @ CNP coated with specific targeting agent is up taken by the cell through endocytosis. Due to low pH and high GSH in endosome, and lysosome drug is released into the cytoplasm and then enter either into nucleus directly and bind with DNA that causes its denaturation or in mitochondria which increased the production of ROS that further attack the nucleus and causes denaturation of DNA, which ultimately lead to cell death

Table 14 Drug delivery

\begin{tabular}{|c|c|c|c|c|}
\hline S. no & Name of drug & Cell type & Observation & References \\
\hline 1. & Carboxybenzene sulphonamide & None & $\begin{array}{l}\text { Showed an inhibition of hCAll which is very } \\
\text { useful in the treatment of glaucoma }\end{array}$ & {$[115]$} \\
\hline 2. & Camptothecin & Human pancreatic cancer cell lines BxPC-3 cells & $\begin{array}{l}\text { Increase in the conc. of camptothecin-loaded } \\
\text { nanoceria decreases the cell viability of } \\
\text { BXPC-3 cells }\end{array}$ & {$[147]$} \\
\hline 3. & Chlorin e6 & $\begin{array}{l}\text { Human breast cancer cells (MCF-7/ADR) and } \\
\text { MCF-7/ADR xenograft murine model }\end{array}$ & $\begin{array}{l}\text { Showed photodynamic therapy in drug-resist- } \\
\text { ant breast cancer cells and tumor in vivo }\end{array}$ & {$[148]$} \\
\hline 4. & Doxorubicin & $\begin{array}{l}\text { Human Ovarian cancer cell lines A2780, SKOV- } \\
\text { 3, and CAOV-3 }\end{array}$ & $\begin{array}{l}\text { Higher cell proliferation inhibition and apopto- } \\
\text { sis compared with free DOX }\end{array}$ & {$[116]$} \\
\hline 5. & $\begin{array}{l}\text { Doxorubicin and Hsp90 inhibi- } \\
\text { tor ganetespib (GT) }\end{array}$ & A549 cells & $\begin{array}{l}\text { Co-delivery of Dox and GT using Nanoceria } \\
\text { showed more than } 80 \% \text { of NSCLC death } \\
\text { within } 48 \text { h of incubation }\end{array}$ & {$[33]$} \\
\hline 6. & Curcumin & $\begin{array}{l}\text { Neuroblastoma cell lines: IMR-32, SMS-KAN, } \\
\text { SK-N-AS, and LA-N-6 }\end{array}$ & $\begin{array}{l}\text { Induce substantial cell death in neuroblastoma } \\
\text { cells }\end{array}$ & {$[34]$} \\
\hline 7. & Doxorubicin & Human liver cancer cells (HepG2 cells) & $\begin{array}{l}\text { Showed a synergistic anticancer effect on } \\
\text { cancer cells }\end{array}$ & {$[52]$} \\
\hline
\end{tabular}

\section{Table 15 Gene delivery}

\begin{tabular}{llll}
\hline S. no & Name of gene & Cell type & Observation \\
\hline 1. & Luc gene, EGFP gene, and RFP gene & HEK293, MCF-7 and Hep G2 cells & $\begin{array}{r}\mathrm{CeO}_{2} / \text { DODAB nanovectors could transfect genes in vitro } \\
\text { and in vivo without causing any toxic effect }\end{array}$ \\
\hline
\end{tabular}


In 2017, Das et al. [116] reported nanoceria-mediated drug delivery of doxorubicin in human ovarian cancer cells. They found that doxorubicin-loaded nanoceria $\left(\mathrm{CeO}_{2} / \mathrm{DOX}\right)$ possessed excellent drug-loading content (22.41\%) and drug release behavior at the acidic and high reducing environment as well as increased cellular uptake and retention of the drug as compared to free doxorubicin. They further showed that doxorubicinloaded nanoceria exhibited a higher degree of apoptosis and cell proliferation inhibition than free doxorubicin in human ovarian cancer cells.

In 2017, Sulthana et al. [33] reported about polyacrylic acid (PAA) coated functional nanoceria loaded with a combination of two therapeutic drugs; Hsp 90 inhibitor, ganetespib (GT) and doxorubicin (doxo) for the treatment of non-small-cell lung cancer (NSCLC). They further conjugated the nanoceria with folic acid to target folate receptors expressing NSCLC. They observed that this combination therapy results in the death of more than $80 \%$ of NSCLC cells within $48 \mathrm{~h}$ of incubation, whereas around $40 \%$ of cell death occurred in the case of single drug-loaded nanoceria. Later, Kalashnikova et al. [34] used dextran-coated nanoceria loaded with curcumin for the treatment of human childhood neuroblastoma and exploring their anti-cancer activities in neuroblastoma models, including both MYCN-amplified and non amplified cell lines. They demonstrated that dextran-coated nanoceria loaded with curcumin-induced significant cytotoxicity in neuroblastoma cells while sparing healthy cells. More recently, Zhang et al. [52] developed a multifunctional and pH/GSH dual-responsive drug delivery system (MDDS) using porous cerium oxide nanorods loaded with doxorubicin for drug delivery in human liver cancer cells (HepG2 cells). This MDDS was further conjugated with lactose derivatives which recognize the asialoglycoprotein receptors present on the surface of liver cancer cells. They observed that the asprepared drug-loaded and targeted MDDS showed a synergistic anticancer effect in HepG2 cells due to low intracellular $\mathrm{pH}$ and high GSH level inside the lysosomes in cancer cells.

The first report of gene delivery using nanoceria as a carrier was published by Das et al. [149] in 2016. They developed dimethyldioctadecylammonium bromide (DODAB)-nanoceria hybrids as an efficient nonviral gene delivery vector for the transfection of plasmid DNA (pEGFPN1) in several cells lines, HEK293, MCF-7, and HepG2. They found that the overall vector performance of DODAB-modified $\mathrm{CeO}_{2}$ nanohybrids $\left(\mathrm{CeO}_{2} / \mathrm{DODAB}\right)$ was comparable with lipofectamine 2000 and DOTAP(1,2-dioleoyloxy-3-trimethylammonium propane) and higher than calcium phosphate and DEAE-dextran used for transfecting small (4.7
KD) plasmids. The higher gene delivery efficiency of this nanohybrid vector was further supported by the improved cellular uptake of the nanovector/DNA complexes through clathrin- and caveolae-mediated endocytosis and their subsequent release from the endosomes. Further, $\mathrm{CeO}_{2} / \mathrm{DODAB}$ nanovectors were also checked for their in vivo transfection efficiency via injecting the plasmid/nanovector complexes into the posterior tibialis muscles of mice. They observed a 3.5 times higher fluorescence intensity with $\mathrm{CeO}_{2} / \mathrm{DODAB}$ compared with the naked DNA treated groups after $72 \mathrm{~h}$, and the transfection efficiency was around $17 \%$ less than the commercial in vivo-jeiPEI reagents. The results obtained from their study showed that nanoceria possessed great potential for its use as a carrier in gene delivery as represented in Fig. 6.

\section{Beneficial effect of nanoceria against diabetes and its associated complications}

Diabetes is one of the most serious and leading health disaster of the 21st century. It is characterized by an increase in plasma glucose concentration due to complications in either insulin secretion, insulin action, or both. The prevalence of diabetes is increasing at an alarming rate causing severe health and economic burden to the patients and the society at large. According to the 2017 reports of International Diabetes Federation (IDF), approximately 425 million people around the world were found to be diabetic and is predicted to increase to 629 million by 2045 (IDF Diabetes Atlas 8th Edition) [150]. Over time, diabetes can lead to several organs and tissue damage ranging from cardiac dysfunction, blindness, renal dysfunction, nerve damage, erectile dysfunction, etc. Oxidative stress has been recognized as a significant contributing factor in the pathogenesis of diabetes and its associated complications [151]. Everyday factors, like unhealthy diets, obesity, aging, etc. have been found to contribute to an oxidative environment, which may cause a decrease in insulin sensitivity, impaired glucose tolerance, and an increase in insulin resistance. Due to its potential antioxidant nature, CNP is gaining acceptance as a prospective therapeutic material against hyperglycemia and its associated complications in diabetes (Fig. 7). The anti-diabetic effect of CNP has been studied by several researchers, as depicted in Table 16.

Khurana et al. [152] examined the antidiabetic effect of cerium oxide nanoparticles (CNPs) by using multiple low doses of streptozotocin (STZ)-induced type 1 diabetic mice. Results demonstrated that treatment with CNPs ( 0.2 and $2 \mathrm{mg} / \mathrm{kg}$ body weight, i.p., 28 days) significantly reduced the plasma glucose levels and improved the glucose tolerance in a dose-dependent manner in diabetic mice. Moreover, CNPs administration also 


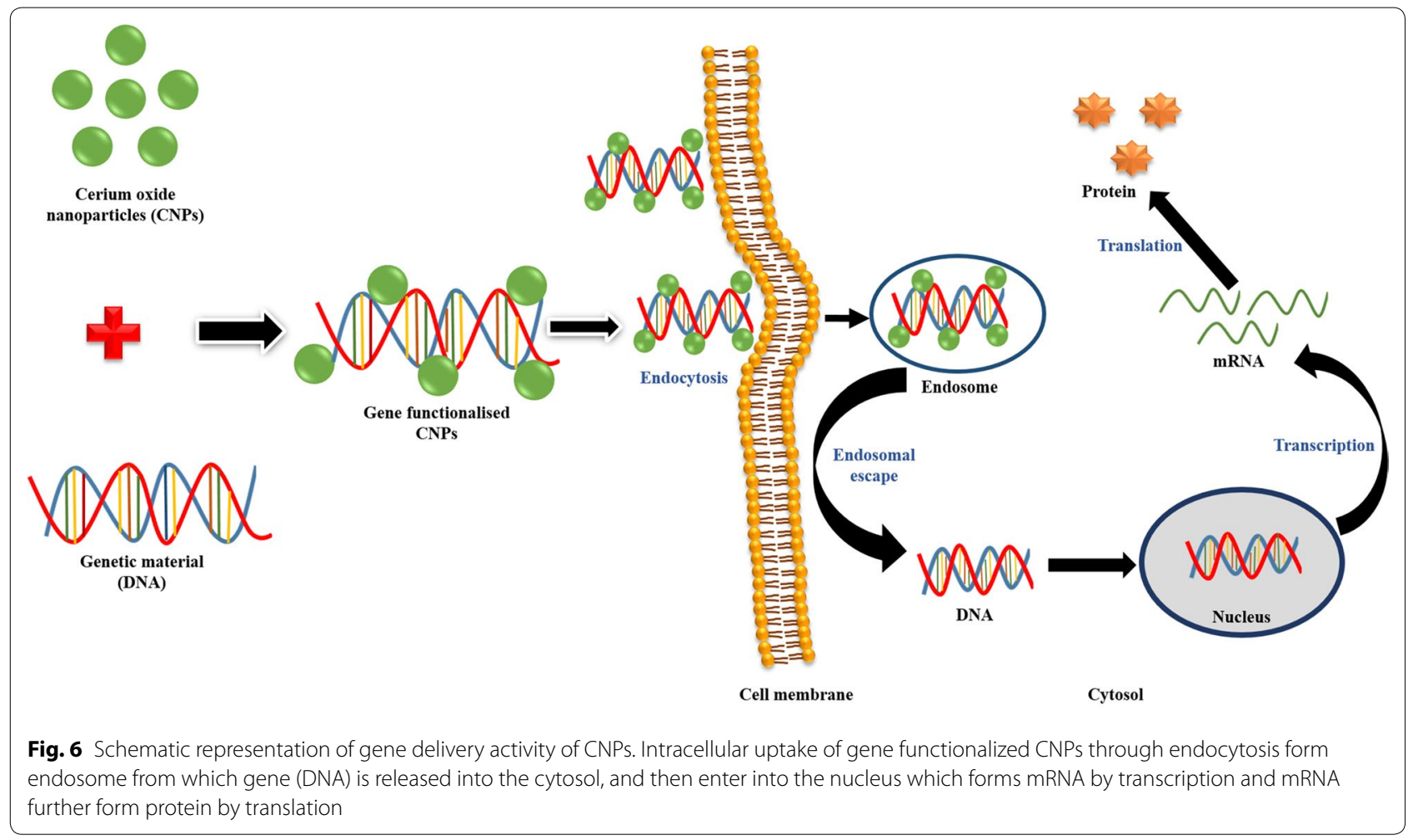

caused an increase in GSH levels and a decrease in lipid peroxidation and NO levels compared to those seen in the pancreatic tissues of the diabetic mice, which suggests a beneficial role of CNPs in preventing the high glucose-induced oxidative and nitrosative stress in diabetic mice. The intervention of CNPs also led to attenuation of the secretion of pro-inflammatory cytokines, namely TNF- $\alpha$ and IL- 6 and an increase in plasma

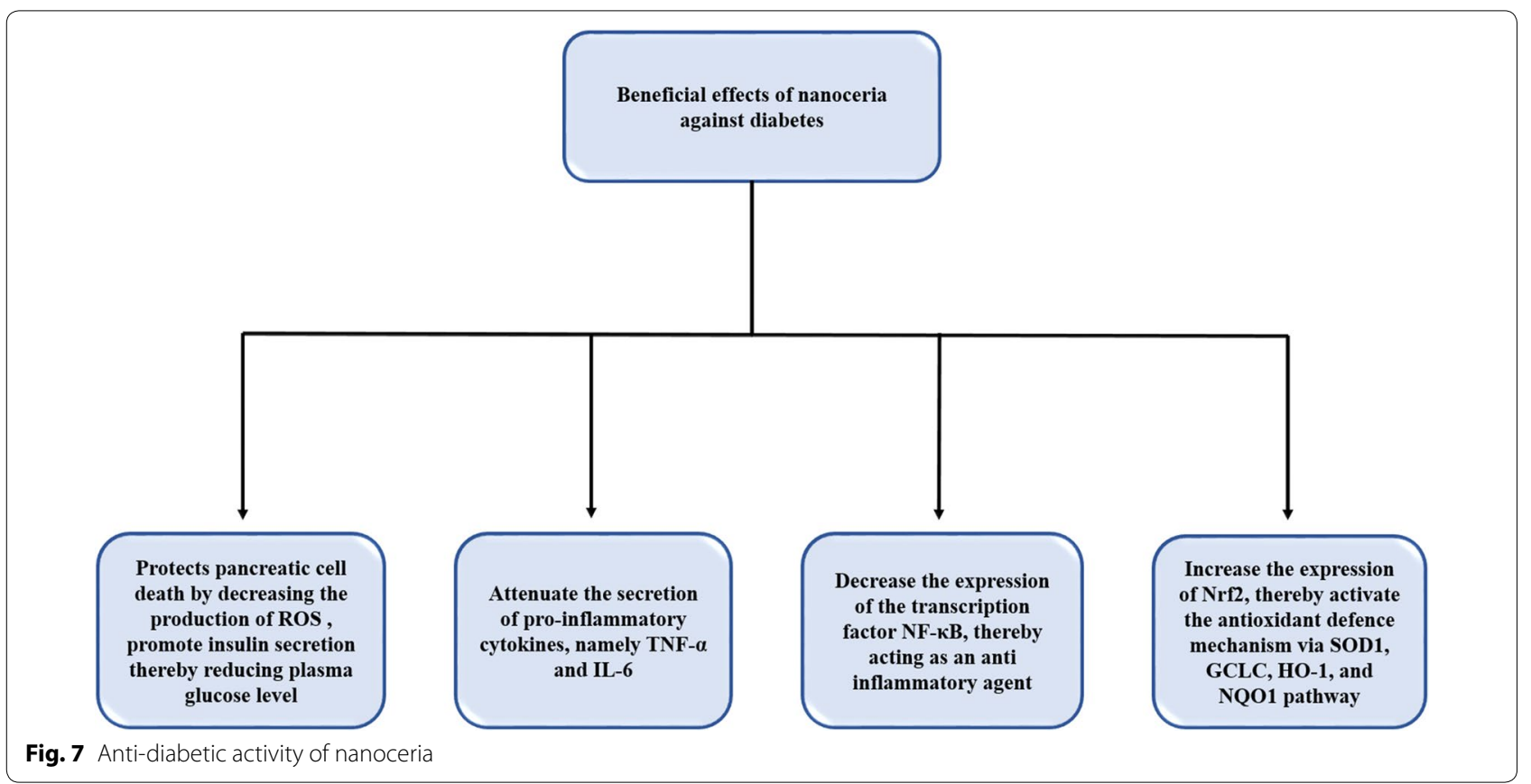


Table 16 Anti-diabetic Effect

\begin{tabular}{|c|c|c|c|c|}
\hline S. no. & Particle size & Model & Observation & References \\
\hline 1. & $\begin{array}{l}180 \pm 15.54 \mathrm{~nm} \text { by DLS } \\
\text { and } 90 \pm 9.5 \mathrm{~nm} \text { by } \\
\text { SEM }\end{array}$ & $\begin{array}{l}\text { STZ-treated diabetic mice were treated with CNPs } \\
(0.2 \text { and } 2 \text { mg/kg bw, i.p., } 28 \text { days })\end{array}$ & $\begin{array}{l}\text { CNPs treatment decreased the glucose levels, lipid } \\
\text { peroxidation, secretion of pro-inflammatory } \\
\text { cytokines, and NF-KB protein expression and } \\
\text { increased the insulin levels and glutathione } \\
\text { concentrations }\end{array}$ & [152] \\
\hline 2. & - & $\begin{array}{l}\text { HepG2 cells were treated with } 50 \mathrm{mM} \text { CNPs } \\
\text { against high glucose }(50 \mathrm{mM}) \text { exposure }\end{array}$ & $\begin{array}{l}\text { Treatment with CNPs significantly decreased the } \\
\text { high glucose-induced cytotoxicity, ROS forma- } \\
\text { tion, lipid peroxidation, and increased intracel- } \\
\text { lular glutathione }\end{array}$ & [153] \\
\hline 3. & - & $\begin{array}{l}\text { STZ-treated diabetic animals were administered } \\
\text { CNPs ( } 30 \mathrm{mg} / \mathrm{kg} \text { bw, daily, i.p., } 2 \text { weeks) }\end{array}$ & $\begin{array}{l}\text { CNPs administration alleviated the plasma glucose } \\
\text { levels and the deleterious effects of diabetes on } \\
\text { the sperm potential fertility, sperm parameters, } \\
\text { DNA integrity, and Nrf2 expression levels }\end{array}$ & [154] \\
\hline 4. & - & $\begin{array}{l}\text { STZ-treated diabetic animals were administered } \\
\text { CNPs ( } 30 \mathrm{mg} / \mathrm{kg} \text { bw, daily, i.p., } 2 \text { weeks) }\end{array}$ & $\begin{array}{l}\text { CNPs administration increased the total antioxi- } \\
\text { dant capacity via upregulating Nrf2 mediated } \\
\text { increase in the mRNA expressions of antioxidant } \\
\text { genes, namely GCLC, HQ-1, and NQO1 }\end{array}$ & [155] \\
\hline 5. & - & $\begin{array}{l}\text { STZ-treated diabetic mice were treated with CNPs } \\
(60 \mathrm{mg} / \mathrm{kg} \text { bw, } 16 \text { days })\end{array}$ & $\begin{array}{l}\text { CNPs treatment significantly prevented embry- } \\
\text { onic oxidative stress and pathologic changes in } \\
\text { diabetic mice }\end{array}$ & [157] \\
\hline 6. & - & $\begin{array}{l}\text { Isolated pancreatic islets were pre-treated with } \\
\operatorname{CNPs}(10,100,1000 \mathrm{nM})\end{array}$ & $\begin{array}{l}\text { Treatment with CNPs increased the cell viability, } \\
\text { secretion of insulin, and ATP/ADP ratio and } \\
\text { reduced the ROS level }\end{array}$ & [158] \\
\hline 7. & - & $\begin{array}{l}\text { Isolated pancreatic islets were pre-treated with } \\
\text { CNPs }(200 \mu \mathrm{M}) \text { against } \mathrm{H}_{2} \mathrm{O}_{2}(50 \mu \mathrm{M}, 2 \mathrm{~h})\end{array}$ & $\begin{array}{l}\text { Pre-treatment with CNPs attenuated the ROS } \\
\text { formation, caspase-3 activity, and apoptotic } \\
\text { cell death and increased cell viability, glucose- } \\
\text { induced ATP production, and glucose-stimu- } \\
\text { lated insulin secretion }\end{array}$ & [159] \\
\hline
\end{tabular}

insulin levels in the diabetic mice. Further mechanistic studies demonstrated a decrease in NF- $\kappa B$ and an increase in Nrf2 and SOD1 protein expression in CNPs treated pancreatic tissues of diabetic mice suggesting a role of $\mathrm{NF}-\mathrm{kB} / \mathrm{Nrf} 2$ signaling pathway in mediating the anti-inflammatory and anti-oxidant potential of CNPs. Both TUNEL assay and immunohistological analysis of cleaved caspase three also demonstrated the reduction of DNA fragmentation and apoptotic cell death in CNPs treated pancreatic tissues of the diabetic mice. Taken all together, the authors reported a potential antidiabetic role of CNPs in STZ-induced type 1 diabetic mice.

The beneficial effect of CNPs against hyperglycemiainduced oxidative damage has been further investigated by using high glucose-treated HepG2 cells [153]. Results showed that high glucose treatment caused a decrease in cell viability, an increase in ROS production and lipid peroxidation, and a decrease in intracellular GSH levels. Pre-treatment with CNPs (0-200 mM) significantly protected the cells from high glucose-induced cytotoxicity, and a maximum protective effect was observed at a dose of $50 \mathrm{mM}$ against $24 \mathrm{~h}$ exposure of high glucose. Treatment with CNPs also reduced the intracellular ROS production and lipid peroxidation and increased the GSH levels in high glucose-treated HepG2 cells suggesting a beneficial role of CNPs against hyperglycemia-induced oxidative impairment in HepG2 cells.

Oxidative stress plays an essential role in the pathophysiology of diabetes associated with impaired reproductive function. Artimani et al. [154] examined the impact of CNPs on the sperm parameters, spermatogenesis, and Nrf2 protein expression in the testicular tissues of the STZ-treated diabetic rodents. It has been observed that treatment with CNPs $(30 \mathrm{mg}$ / kg bw, daily, i.p., 2 weeks) significantly decreased the plasma glucose levels and increased the sperm count and mortality compared to those seen in STZ-treated diabetic animals. Furthermore, CNPs administration significantly elevated the plasma levels of LH and FSH but not testosterone in diabetic animals. Histological findings revealed that CNPs treatment significantly declined seminiferous tubule abnormality, increased the number of Leydig cells, and improved the testicular physiology. An increase in Nrf2 mRNA expression and a decrease in sperm head DNA fragmentation in diabetic animals after CNPs treatment also supported the beneficial role of CNPs in preventing the reproductive dysfunction associated with diabetes. In another study, Artimani et al. [155] further examined the impact of CNPs administration on the oxidative stress status 
and expression of anti-oxidative genes related to $\mathrm{Nrf} 2$ signaling pathway, namely $\mathrm{HO}-1, \mathrm{GCLC}$, and NQO1 in testes tissues of STZ-induced diabetic rats. Results demonstrated that CNPs administration $(30 \mathrm{mg} / \mathrm{kg}$ body weight, daily, i.p., 2 weeks) alleviated the deleterious effect of diabetes via increasing the total antioxidant capacity and decreasing the total oxidative stress in the testicular tissues of the diabetic rats. Treatment with CNPs also caused a decrease in the mRNA expression of the antioxidant genes, HO-1, GCLC, and NQO1 compared to those seen in the diabetic group and the authors also a positive correlation between Nrf2 and HO-1, GCLC, or NQO1, which suggests a critical role of Nrf2-dependent antioxidant response in mediating the underlying mechanisms associated the protective effect of CNPs in diabetes testes.

Gestational diabetes increases the incidences of congenital anomalies, premature birth, fetal macrosomia, neonatal hyperglycaemia, and infant death [156]. Oxidative stress has been implicated in the pathogenesis of diabetic embryopathy. Recently, Vafaei-Pour et al. [157] examined the embryo-protective effect of CNPs by using STZ-induced diabetic female mice model. Results showed that administration of CNPs $(60 \mathrm{mg} / \mathrm{kg}$ body weight, 16 days) significantly inhibited the embryonic oxidative stress in diabetic mice as revealed by the decrease in ROS formation, lipid peroxidation, and protein carbonylation and the increase in GSH level and catalase activity compared to those seen in the diabetic group. Moreover, CNPs treatment partially restored the hyperglycemia-induced malformation in visceral and spinal of the embryo. Combining all, the results suggest a beneficial role of CNPs treatment in preventing diabetic embryopathy.

Pancreatic islet transplantation has been recognized as a promising treatment strategy for patients with insulin dependent diabetes mellitus (IDDM). Despite recent improvements, the loss of healthy islet at the end of the operation is the main restriction, and this may be due to the generation of excessive oxidative stress during isolation and transplantation procedures. Inherently low levels of antioxidant capacity, scarcity of vascular system, and hypoxic ischemia are playing an essential role in making these cells vulnerable for oxidative damage. Abdollahi et al. [158] have examined the beneficial effect of CNPs combined with sodium selenite in improving the biochemical function of isolated rat pancreatic islets. It has been observed that treatment with CNPs (100 nM) along with sodium selenite nanoparticles significantly increased the cell viability, insulin secretion, and ATP/ ADP ratio and decreased the ROS production in the isolated rodent pancreatic islets compared to those seen in CNPs or sodium selenite alone treated cells. These results suggest a beneficial role of CNPs along with sodium selenite in improving the transplantation outcome of pancreatic islets. In another study, Abdollahi et al. [159] further investigated the beneficial role of CNPs along with yttrium oxide nanoparticles in preventing the $\mathrm{H}_{2} \mathrm{O}_{2}$ induced oxidative impairment in isolated rodent pancreatic islets. Results demonstrated that CNPs treatment $(200 \mu \mathrm{M})$ with or without yttrium oxide against $\mathrm{H}_{2} \mathrm{O}_{2}$ exposure $(50 \mu \mathrm{M}, 2 \mathrm{~h})$ significantly reduced the intracellular ROS formation and increased the cell viability, glucose-induced ATP production, and glucose-stimulated insulin secretion in isolated pancreatic islets. Interestingly, treatment with CNPs with or without yttrium oxide also caused a reduction in caspase- 3 and caspase- 9 activities followed by a decrease in apoptotic cell death (examined by Hoechst staining) in $\mathrm{H}_{2} \mathrm{O}_{2}$-treated cells. In conclusion, results suggested that treatment with CNPs with or without yttrium oxide may protect the pancreatic cell death via improving the oxidative stress-mediated apoptotic pathway.

\section{Nanoceria directed stem cell differentiation for tissue regeneration}

Nanoceria has also been used as an excellent therapeutic agent in tissue repair and regeneration. The tissue repairment ability of nanoceria is due to its ROS scavenging property and angiogenic potentials. Further, nanoceria can also induce stem cell differentiation, which helps in tissue regeneration [160]. Karakoti et al. [77] studied the role of nanoceria in bone regeneration by using human mesenchymal stem cells (HMSCs). They incorporated nanoceria in bioactive glass foam scaffolds which were further compared with bioactive scaffolds without nanoceria. They showed that the as-prepared nanoceria was non-toxic to the HMSCs, and the bioactive scaffolds containing nanoceria increased the production of collagen and enhanced the osteoblastic differentiation of HMSCs after 10 days of culture because of its oxygen buffering property. In 2015, Zhang et al. [161] used primary mouse bone marrow stromal cells (BMSCs) and examined the effect of nanoceria on the osteogenic and adipogenic differentiation. They showed that nanoceria is non-toxic towards BMSCs when incubated for 24 and $72 \mathrm{~h}$. They further showed that nanoceria exhibit both concentration and time-dependent differentiation of the BMSCs into osteoblasts and adipocytes. Recently, Marino et al. [141] in 2017 prepared highly-aligned nanocomposite fibers of gelatin/nanoceria as antioxidant scaffolds for nerve regeneration. They examined the effect of these nanofibres on neuron-like SH-SY5Y cells. They showed that the as-prepared substrates were able to sustain the growth and differentiation of neuronal cells due to the scaffolds topography as well as antioxidant nature. 
Table 17 Tissue regeneration activity

\begin{tabular}{|c|c|c|c|c|}
\hline S. no & Therapeutic target tissue & Cell type & Observation & References \\
\hline 1. & Bone & Human mesenchymal stem cells (HMSCs) & $\begin{array}{l}\text { Bioactive scaffolds containing nanoceria increased the } \\
\text { production of collagen and enhanced the osteoblastic } \\
\text { differentiation of HMSCs }\end{array}$ & {$[77]$} \\
\hline 2. & Bone and soft tissue & Bone marrow stromal cells (BMSCs) & $\begin{array}{l}\text { Nanoceria increased the viability of BMSCs and also } \\
\text { showed concentration and time-dependent prolifera- } \\
\text { tion, osteogenic, and adipogenic differentiation of } \\
\text { BMSCs }\end{array}$ & [161] \\
\hline 3. & Nerve & Neuron-like SH-SY5Y cells & $\begin{array}{l}\text { Gelatin/nanoceria nanocomposite fibers improved the } \\
\text { growth and differentiation of neuronal cells }\end{array}$ & {$[141]$} \\
\hline
\end{tabular}

All these studies indicated that nanoceria could be used as a composite scaffold for the regeneration of bone, adipose, and nerve tissues, as mentioned in Table 17.

\section{Adverse effects of nanoceria}

Despite showing various promising biomedical applications, nanoceria also shows some toxic effects, which are currently a significant concern. Therefore, risk assessment of workplace exposure to these engineered nanoparticles should be a significant issue. Besides, risk assessment can also be applied to the product in which these nanoparticles are incorporated.

The toxicity of nanoceria depends upon various factors, such as particle size, preparation method, cell type, dose/concentration, exposure time, and exposure route [162]. Aalapati et al. [163] studied the toxic effects and bio-accumulation of nanoceria in CD1 mice and observed that nasal inhalation exposure of nanoceria results in pulmonary and extrapulmonary toxicity in CD1 mice. Wu et al. [164] studied the size-dependent toxicity of nanoceria on mice after repeated intranasal instillation. Two different sized nanoceria $(7 \mathrm{~nm}$ and $25 \mathrm{~nm}$ ) were used in their experiment to study the toxic effect of nanoceria in the lung, liver, spleen, kidney, and brain of mice. They observed size-dependent pulmonary damage for nanoceria. On the other hand, both sized nanoceria showed similar systemic toxicity to other organs.

In 2014, Kumari et al. [165] analyzed the genotoxicity by providing repeated oral administration of 30,300 and $600 \mathrm{mg} / \mathrm{kg}$ body weight per day of nanoceria and cerium oxide microparticles for 28 days in Wistar rats. They observed that nanoceria exhibited toxic effects without any severe distress symptoms and mortality at medium and high doses. On the other hand, microparticles did not show any toxicity. They observed that long-term exposure of nanoceria at higher conc. caused genetic damage (DNA damage in peripheral blood leukocytes and liver), histological changes (alterations in liver, spleen, and brain) and biochemical alterations (alterations in lactate dehydrogenase and alkaline phosphatase activity in serum and also reduction in glutathione content in liver, kidney, and brain) in rats.

Nanoceria also shows immunotoxicological effects by interfering with the immune system. Ranjbar et al. [166] studied the dose-dependent effect of nanoceria on rat liver by giving them the intraperitoneal injection. In their study, they observed that nanoceria with a dose of $15 \mathrm{mg} /$ $\mathrm{kg}$ body weight acted as an antioxidant, thereby preventing oxidative stress. Besides, it also decreased the level of inflammatory cytokines, such as IL-17 and TNF- $\alpha$ in the rat liver, which suppressed the inflammatory response. In contrast, they also observed that nanoceria with doses of 30 and $60 \mathrm{mg} / \mathrm{kg}$ body weight showed an increase in the level of IL-17 and TNF- $\alpha$, thereby developed inflammation and immunotoxicity in the rat liver tissue.

In 2018, Gagnon et al. [167] observed that the exposure of nanoceria in natural water caused immunotoxicity in rainbow trout fish. They found that when the fishes were exposed to the water, nanoceria got accumulated in their gills. The accumulation was highest in green water that possesses higher $\mathrm{pH}$, higher conductivity, and contained less total organic carbon as compared to brown water. Therefore, nanoceria induced phagocytosis in fish exposed to tap and green water but not in brown water.

\section{Conclusion and future perspectives}

Nanoceria has been found to possess great potential for a broad range of applications, particularly in the biomedical field. In this review, different methods used for the synthesis of nanoceria have been discussed along with its biomedical applications. Among the existing methods, nowadays, green synthesis method has been widely focused by the researchers to synthesize nanoceria that uses biocompatible stabilizers and produce less toxic effects. These methods are considered very important in order to understand the actual physiochemical properties of nanoceria. The paper exclusively focuses on the biomedical applications of nanoceria, in which its antibacterial, antioxidant, anticancer, drug/gene delivery, 
antidiabetic, and tissue regeneration activities have been discussed. Nanoceria has been found to exert a profound antibacterial effect against different strains of bacteria. The usefulness of nanoceria depends upon its inherent property of showing variable oxidation states, due to which it can act as an excellent antioxidant agent and protect the healthy cells from oxidative stress.

On the other hand, in cancer cells (under low pH environment), it acts as a pro-oxidant by producing reactive oxygen species and kills cancer cells. Nanoceria has also been used as a carrier for drug and gene delivery into specific target cells and can be helpful in the treatment of various types of diseases. Nanoceria confers protection to the ROS-mediated damage of pancreatic beta cells, thereby could promote insulin secretion, reduced plasma glucose levels and thereby showed a beneficial effect against diabetes-induced organ pathophysiology via decreasing the level of intracellular ROS. Besides, nanoceria also exhibits excellent potential in the field of tissue regeneration by directed stem cell differentiation.

Although there are numerous reports on antibacterial and antioxidant activities of nanoceria, there is minimal research on its anticancer, drug/gene delivery, anti-diabetic, and tissue regeneration applications. So, we should further explore the use of nanoceria as

- An anticancer agent for the treatment of all kinds of cancer which is one of the most challenging tasks,

- A targeted drug and gene delivery agent for the treatment of various life-threatening diseases, like cancer, cardiac disease, and Alzeimer's disease, etc.

- An anti-diabetic agent to treat diabetes mellitus and its associated organ dysfunction which is one of the significant health problems worldwide, and

- A useful scaffold in tissue regeneration field.

Based on these considerations, the use of nanoceria needs to be further explored so that it can be used as an active therapeutic agent in biomedicine.

\section{Abbreviations}

BMSCs: bone marrow stromal cells; CAT: catalase; CNP: cerium oxide nanoparticle; CTAB: cetyltrimethylammonium bromide; DODAB: dimethyldioctadecylammonium bromide; DOTAP: 1,2-dioleoyloxy-3-trimethylammonium propane; HMSCs: human mesenchymal stem cells; hCAll: human carbonic anhydrase enzymell; IDDM: insulin dependent diabetes mellitus; IDF: international diabetes federation; MSN: mesoporous silica nanoparticle; NSCLC: nonsmall-cell lung cancer; PPCNPs: polyethylenimine-PEGylation ceria nanoparticles; PAA: polyacrylic acid; PVP: polyvinyl pyrrolidone; ROS: reactive oxygen species; SHS: self-propagating high-temperature synthesis; SOD: superoxide dismutase; STZ: streptozotocin.
\end{abstract}

\section{Acknowledgements}

Authors would like to acknowledge the Scientific Writing Cell, Shoolini University for the support provided towards language editing of the manuscript.

\section{Authors' contributions}

NT, PM, and JD contributed equally to the research and review of literature, organization, and writing of this review article. All authors read and approved the final manuscript.

\section{Funding}

Our research study did not receive any specific grant from funding agencies.

\section{Availability of data and materials}

Not applicable.

Ethics approval and consent to participate

Not applicable.

Consent for publication

Not applicable.

Competing interests

The authors declare that they have no competing interests.

Received: 11 May 2019 Accepted: 4 July 2019

Published online: 10 July 2019

\section{References}

1. Fard JK, Jafari S, Eghbal MA. A review of molecular mechanisms involved in toxicity of nanoparticles. Adv Pharm Bull. 2015;5(4):447-54. https://doi.org/10.15171/apb.2015.061.

2. Ju-Nam Y, Lead JR. Manufactured nanoparticles: an overview of their chemistry, interactions and potential environmental implications. Sci Total Environ. 2008;400(1-3):396-414. https://doi.org/10.1016/j.scito tenv.2008.06.042.

3. Wang EC, Wang AZ. Nanoparticles and their applications in cell and molecular biology. Integr Biol (United Kingdom). 2014;6(1):9-26.

4. Husseini GA, Pitt WG. Micelles and nanoparticles for ultrasonic drug and gene delivery. Adv Drug Deliv Rev. 2008;60(10):1137-52.

5. Lu AH, Salabas EL, Schüth F. Magnetic nanoparticles: synthesis, protection, functionalization, and application. Angew Chemie Int Ed. 2007:46(8):1222-44.

6. Khan I, Saeed K, Khan I. Nanoparticles: properties, applications and toxicities. Arab J Chem. 2017;1:1. https://doi.org/10.1016/j.arabj c.2017.05.011.

7. Salata OV. Applications of nanoparticles in biology and medicine. J Nanobiotechnol. 2004;2:3.

8. Tiwari DK, Behari J, Sen P. Application of nanoparticles in waste water treatment. World Appl Sci J. 2008;47:3931-46.

9. Puzyn T, Rasulev B, Gajewicz A, Hu X, Dasari TP, Michalkova A, et al. Using nano-QSAR to predict the cytotoxicity of metal oxide nanoparticles. Nat Nanotechnol. 2011;6(3):175-8.

10. Dahle JT, Arai Y. Environmental geochemistry of cerium: applications and toxicology of cerium oxide nanoparticles. Int J Environ Res Public Health. 2015;12(2):1253-78.

11. Karakoti AS, Kuchibhatla SVNT, Babu KS, Seal S. Direct synthesis of nanoceria in aqueous polyhydroxyl solutions. J Phys Chem C. 2007;111(46):17232-40.

12. Dhall A, SelfW. Cerium oxide nanoparticles: a brief review of their synthesis methods and biomedical applications. Antioxidants. 2018;7(8):97.

13. Pirmohamed T, Dowding JM, Singh S, Wasserman B, Heckert E, Karakoti AS, et al. Nanoceria exhibit redox state-dependent catalase mimetic activity. Chem Commun. 2010;46(16):2736-8.

14. Estevez AY, Erlichman JS. The potential of cerium oxide nanoparticles (nanoceria) for neurodegenerative disease therapy. Nanomedicine. 2014;9(10):1437-40

15. Korsvik C, Patil S, Seal S, SelfWT. Superoxide dismutase mimetic properties exhibited by vacancy engineered ceria nanoparticles. Chem Commun. 2007;10:1056-8.

16. Hirst SM, Karakoti A, Singh S, Self W, Tyler R, Seal S, et al. Bio- distribution and in vivo antioxidant effects of cerium oxide nanoparticles in mice. Environ Toxicol. 2013;28:107. 
17. Jacobs G, Williams L, Graham U, Sparks D, Davis BH. Low-temperature water-gas shift: in-situ DRIFTS — reaction study of a Pt/CeO 2 catalyst for fuel cell reformer applications. J Phys Chem B. 2003;107(38):10398-404.

18. Goubin F, Rocquefelte $X$, Whangbo M, Montardi Y, Brec R, Jobic S. Experimental and Theoretical Characterization of the the optical properties of $\mathrm{CeO}_{2}, \mathrm{SrCeO}_{3}$, and $\mathrm{Sr}_{2} \mathrm{CeO}_{4}$ containing $\mathrm{Ce} 4+$ (fo) ions. Chem Mater. 2004;16(4):662-9.

19. Jasinski P, Suzuki T, Anderson HU. Nanocrystalline undoped ceria oxygen sensor. Sensors Actuators B Chem. 2003;95(1-3):73-7.

20. Trovarelli A. Catalytic properties of ceria and $\mathrm{CeO}_{2}$-containing materials. Catal Rev Sci Eng. 1996;38(4):439-520.

21. Dao NN, Luu MD, Nguyen QK, Kim BS. UV absorption by cerium oxide nanoparticles/epoxy composite thin films. Adv Nat Sci Nanosci Nanotechnol. 2011;2(4):4-8.

22. Sohlberg K, Pantelides ST, Pennycook SJ. Interactions of hydrogen with $\mathrm{CeO}_{2}$. J Am Chem Soc. 2001;123(27):6609-11.

23. Shchukin DG, Caruso RA. Template synthesis and photocatalytic properties of porous metal oxide spheres formed by nanoparticle infiltration. Chem Mater. 2004;16(11):2287-92.

24. Younce CW, Wang K, Kolattukudy PE. Hyperglycaemia-induced cardiomyocyte death is mediated via MCP-1 production and induction of a novel zinc-finger protein MCPIP. Cardiovasc Res. 2010;87(4):665-74.

25. Xu C, Qu X. Cerium oxide nanoparticle: a remarkably versatile rare earth nanomaterial for biological applications. NPG Asia Mater. 2014;6(3):e90. https://doi.org/10.1038/am.2013.88

26. Rajeshkumar S, Naik P. Synthesis and biomedical applications of Cerium oxide nanoparticles-a review. Biotechnol Rep. 2018;17:1-5. https:// doi.org/10.1016/j.btre.2017.11.008

27. Kargozar S, Baino F, Hoseini SJ, Hamzehlou S, Darroudi M, Verdi J, et al. Biomedical applications of nanoceria: new roles for an old player. Nanomedicine. 2018;13(23):3051-69.

28. Terribile D, Trovarelli A, Llorca J, De Leitenburg C, Dolcetti G. The synthesis and characterization of mesoporous high-surface area. J Catal. 1998;178(1):299-308.

29. Tsai MS. Powder synthesis of nano grade cerium oxide via homogenous precipitation and its polishing performance. Mater Sci Eng B Solid-State Mater Adv Technol. 2004;110(2):132-4.

30. Kamruddin M, Ajikumar PK, Nithya R, Tyagi AK, Raj B. Synthesis of nanocrystalline ceria by thermal decomposition and soft-chemistry methods. Scr Mater. 2004;50(4):417-22.

31. Du N, Zhang H, Chen B, Ma X, Yang D. Ligand-free self-assembly of ceria nanocrystals into nanorods by oriented attachment at low temperature. J Phys Chem C. 2007;111(34):12677-80.

32. Farahmandjou M, Zarinkamar M, Firoozabadi TP. Synthesis of cerium oxide $\left(\mathrm{CeO}_{2}\right)$ nanoparticles using simple CO-precipitation method. Rev Mex física. 2016;62:496-9.

33. Sulthana S, Banerjee T, Kallu J, Vuppala SR, Heckert B, Naz S, et al. Combination therapy of NSCLC using Hsp90 inhibitor and doxorubicin carrying functional nanoceria. Mol Pharm. 2017;14(3):875-84.

34. Kalashnikova I, Mazar J, Neal CJ, Rosado AL, Das S, Westmoreland TJ, et al. Nanoparticle delivery of curcumin induces cellular hypoxia and ROS-mediated apoptosis: via modulation of Bcl-2/Bax in human neuroblastoma. Nanoscale. 2017:9(29):10375-87.

35. Perez JM, Asati A, Nath S, Kaittanis C. Synthesis of biocompatible dextran-coated nanoceria with $\mathrm{pH}$-dependent antioxidant properties. Small. 2008:4(5):552-6.

36. Kumar A, Babu S, Karakoti AS, Schulte A, Seal S. Luminescence properties of europium-doped cerium oxide nanoparticles: role of vacancy and oxidation states. Langmuir. 2009;25(18):10998-1007.

37. Zhang QL, Yang ZM, Ding BJ. Synthesis of cerium oxide nanoparticles by the precipitation method. Mater Sci Forum. 2009;610-613(3):233-8.

38. Ketzial JJ, Nesaraj AS. Synthesis of $\mathrm{CeO}_{2}$ nanoparticles by chemical precipitation and the effect of a sur-factant on the distribution of particle sizes. J Ceram Process Res. 2011;12(1):74-9.

39. Renuka NK. Structural characteristics of quantum-size ceria nano particles synthesized via simple ammonia precipitation. J Alloys Compd. 2012;513:230-5. https://doi.org/10.1016/j.jallcom.2011.10.027.

40. Suresh R, Ponnuswamy V, Mariappan R. Effect of annealing temperature on the microstructural, optical and electrical properties of $\mathrm{CeO}_{2}$ nanoparticles by chemical precipitation method. Appl Surf Sci. 2013;273:457-64. https://doi.org/10.1016/j.apsusc.2013.02.062.
41. Nesakumar N, Sethuraman S, Krishnan UM, Rayappan JBB. Fabrication of lactate biosensor based on lactate dehydrogenase immobilized on cerium oxide nanoparticles. J Colloid Interface Sci. 2013;410:158-64. https://doi.org/10.1016/j.jcis.2013.08.009.

42. Babitha KK, Sreedevi A, Priyanka KP, Sabu B, Varghese T. Structural characterization and optical studies of CeO nanoparticles synthesized by chemical precipitation. Indian J Pure Appl Phys. 2015;53(9):596-603.

43. Sun C, Li H, Wang Z, Chen L, Huang X. Synthesis and characterization of polycrystalline $\mathrm{CeO}_{2}$ nanowires. Chem Lett. 2004;33(6):662-3.

44. Sujana MG, Chattopadyay KK, Anand S. Characterization and optical properties of nano-ceria synthesized by surfactant-mediated precipitation technique in mixed solvent system. Appl Surf Sci. 2008;254(22):7405-9.

45. Shelkar R, Sarode S, Nagarkar J. Nano ceria catalyzed synthesis of substituted benzimidazole, benzothiazole, and benzoxazole in aqueous media. Tetrahedron Lett. 2013;54(51):6986-90. https://doi.org/10.1016/j. tetlet.2013.09.092

46. Rahdar A, Aliahmad M, Hajinezhad MR, Samani M. Xanthan gum-stabilized nano-ceria: green chemistry based synthesis, characterization, study of biochemical alterations induced by intraperitoneal doses of nanoparticles in rat. J Mol Struct. 2018;1173:166-72.

47. Masui T, Hirai H, Imanaka N, Adachi G, Sakata T, Mori H. Synthesis of cerium oxide nanoparticles by hydrothermal crystallization with citric acid. J Mater Sci Lett. 2002;21(6):489-91.

48. Renu G, Divya Rani VV, Nair SV, Subramanian KRV, Lakshmanan VK. Development of cerium oxide nanoparticles and its cytotoxicity in prostate cancer cells. Adv Sci Lett. 2012;6:17-25.

49. Mai H, Sun L, Zhang Y, Si R, Feng W, Zhang H. Shape-selective synthesis and oxygen storage behavior of ceria nanopolyhedra, nanorods, and nanocubes. J Phys Chem B. 2005;24:380-5.

50. Zhou K, Wang X, Sun X, Peng Q, Li Y. Enhanced catalytic activity of ceria nanorods from well-defined reactive crystal planes. J Catal. 2005:229(1):206-12

51. Gao W, Zhang Z, Li J, Ma Y, Qu Y. Surface engineering on $\mathrm{CeO}_{2}$ nanorods by chemical redox etching and their enhanced catalytic activity for $\mathrm{CO}$ oxidation. Nanoscale. 2015;7(27):11686-91.

52. Zhang Y, Wu X, Hou C, Shang K, Yang K, Tian Z, et al. Dual-responsive dithio-polydopamine coated porous $\mathrm{CeO}_{2}$ nanorods for targeted and synergistic drug delivery. Int J Nanomed. 2018;13:2161-73.

53. Patil S, Sandberg A, Heckert E, Self W, Seal S. Protein adsorption and cellular uptake of cerium oxide nanoparticles as a function of zeta potential. Biomaterials. 2007:28(31):4600-7.

54. Zhou F, Zhao X, Xu H, Yuan C. CeO2 spherical crystallites: synthesis, formation mechanism, size control, and electrochemical property study. J Phys Chem C. 2007;111(4):1651-7.

55. Sutradhar N, Sinhamahapatra A, Pahari S, Jayachandran M, Subramanian B, Bajaj HC, et al. Facile low-temperature synthesis of ceria and samarium-doped ceria nanoparticles and catalytic allylic oxidation of cyclohexene. J Phys Chem C. 2011;115(15):7628-37.

56. Maensiri S, Masinghboon C, Laokul P, Jareonboon W, Promarak V, Anderson $\mathrm{PL}$, et al. Egg white synthesis and photoluminescence of platelike clusters of $\mathrm{CeO}_{2}$ nanoparticles. Cryst Growth Des. 2007;7:950-5.

57. Kargar H, Ghazavi H, Darroudi M. Size-controlled and bio-directed synthesis of ceria nanopowders and their in vitro cytotoxicity effects. Ceram Int. 2015:41(3):4123-8. https://doi.org/10.1016/j.ceram int.2014.11.108

58. Arumugam A, Karthikeyan C, Haja Hameed AS, Gopinath K, Gowri S, Karthika V. Synthesis of cerium oxide nanoparticles using Gloriosa superba $\mathrm{L}$ leaf extract and their structural, optical and antibacterial properties. Mater Sci Eng C. 2015;49:408-15. https://doi.org/10.1016/j. msec.2015.01.042

59. Kannan SK, Sundrarajan M. A Green approach for the synthesis of a cerium oxide nanoparticle: characterization and antibacterial activity. Int J Nanosci. 2014;13(03):1450018.

60. SaiPriya G, Kanneganti A, Kumar KA, Rao KV, Bykkam S. Bio synthesis of cerium oxide nanoparticles using aloe barbadensis miller gel. Int J Sci Res Publ. 2014;4(1):2250-3153.

61. Maqbool Q, Nazar M, Naz S, Hussain T, Jabeen N, Kausar R, et al. Antimicrobial potential of green synthesized $\mathrm{CeO}_{2}$ nanoparticles from Olea europaea leaf extract. Int J Nanomed. 2016;11:5015-25. 
62. Thovhogi N, Diallo A, Gurib-Fakim A, Maaza M. Nanoparticles green synthesis by Hibiscus Sabdariffa flower extract: main physical properties. J Alloys Compd. 2015;647:392-6. https://doi.org/10.1016/j.jallc om.2015.06.076.

63. Munusamy S, Bhakyaraj K, Vijayalakshmi L, Stephen A, Narayanan V. Synthesis and characterization of cerium oxide nanoparticles using Curvularia lunata and their antibacterial properties. Int J Innov Res Sci Eng. 2014;2(1):318-23.

64. Kargar H, Ghasemi F, Darroudi M. Bioorganic polymer-based synthesis of cerium oxide nanoparticles and their cell viability assays. Ceram Int. 2015;41(1):1589-94. https://doi.org/10.1016/j.ceramint.2014.09.095.

65. Darroudi M, Sarani M, Kazemi Oskuee R, Khorsand Zak A, Amiri MS. Nanoceria: Gum mediated synthesis and in vitro viability assay. Ceram Int. 2014;40(2):2863-8. https://doi.org/10.1016/j.ceramint.2013.10.026.

66. Darroudi M, Sarani M, Kazemi Oskuee R, Khorsand Zak A, Hosseini HA, Gholami L. Green synthesis and evaluation of metabolic activity of starch mediated nanoceria. Ceram Int. 2014;40(1):2041-5. https://doi. org/10.1016/j.ceramint.2013.07.116.

67. Darroudi M, Hoseini SJ, Kazemi Oskuee R, Hosseini HA, Gholami L, Gerayli S. Food-directed synthesis of cerium oxide nanoparticles and their neurotoxicity effects. Ceram Int. 2014;40(5):7425-30. https://doi. org/10.1016/j.ceramint.2013.12.089.

68. Patil SN, Paradeshi JS, Chaudhari PB, Mishra SJ, Chaudhari BL. Biotherapeutic potential and cytotoxicity assessment of pectin-mediated synthesized nanostructured cerium oxide. Appl Biochem Biotechnol. 2016;180(4):638-54. https://doi.org/10.1007/s12010-016-2121-9.

69. Lee JS, Choi SC. Crystallization behavior of nano-ceria powders by hydrothermal synthesis using a mixture of $\mathrm{H}_{2} \mathrm{O}_{2}$ and $\mathrm{NH}_{4} \mathrm{OH}$. Mater Lett. 2004:58(3-4):390-3.

70. Karakoti AS, Singh S, Kumar A, Malinska M, Kuchibhatla SVN, Wozniak $K$, et al. PEGylated nanoceria as radical scavenger with tunable redox chemistry. J Am Chem Soc. 2009;131:14144-5.

71. Alili L, Sack M, von Montfort C, Giri S, Das S, Carroll KS, et al. Downregulation of tumor growth and invasion by redox-active nanoparticles. Antioxid Redox Signal. 2012;19(8):765-78.

72. Zhou K, Yang Z, Yang S. Highly reducible $\mathrm{CeO}_{2}$ nanotubes. Chem Mater. 2007;19(6):1215-7.

73. Zhou X, Wong LL, Karakoti AS, Seal S, McGinnis JF. Nanoceria inhibit the development and promote the regression of pathologic retinal neovascularization in the VIdlr knockout mouse. PLoS ONE. 2011;6:2

74. Wong LL, Hirst SM, Pye QN, Reilly CM, Seal S, McGinnis JF. Catalytic nanoceria are preferentially retained in the rat retina and are not cytotoxic after intravitreal injection. PLoS ONE. 2013;8:3.

75. Giri S, Karakoti A, Graham RP, Maguire JL, Reilly CM, Seal S, et al. Nanoceria: a rare-earth nanoparticle as a novel anti-angiogenic therapeutic agent in ovarian cancer. PLOS ONE. 2013:8:1.

76. Karakoti AS, Monteiro-Riviere NA, Aggarwal R, Davis JP, Narayan RJ, Self WT, et al. Nanoceria as antioxidant : synthesis and biomedical applications. Jom. 2008:60(3):33-7.

77. Karakoti AS, Tsigkou O, Yue S, Lee PD, Stevens MM, Jones JR, et al. Rare earth oxides as nanoadditives in 3-D nanocomposite scaffolds for bone regeneration. J Mater Chem. 2010;20(40):8912-9.

78. Asati A, Santra S, Kaittanis C, Nath S, Perez JM. Oxidase-like activity of polymer-coated cerium oxide nanopartieles. Angew Chemie Int Ed. 2009:48(13):2308-12.

79. Pierscionek BK, Li Y, Yasseen AA, Colhoun LM, Schachar RA, Chen W. Nanoceria have no genotoxic effect on human lens epithelial cells. Nanotechnology. 2010;21:3.

80. Xu H, Zeiger BW, Suslick KS. Sonochemical synthesis of nanomaterials. Chem Soc Rev. 2013;42(7):2555-67.

81. Yin L, Wang Y, Pang G, Koltypin Y, Gedanken A. Sonochemical synthesis of cerium oxide nanoparticles-effect of additives and quantum size effect. J Colloid Interface Sci. 2002;246(1):78-84.

82. Wang H, Zhu JJ, Zhu JM, Liao XH, Xu S, Ding T, et al. Preparation of nanocrystalline ceria particles by sonochemical and microwave assisted heating methods. Phys Chem Chem Phys. 2002;4(15):3794-9.

83. Dutta DP, Manoj N, Tyagi AK. White light emission from sonochemically synthesized rare earth doped ceria nanophosphors. J Lumin. 2011;131(8):1807-12. https://doi.org/10.1016/j.jumin.2011.04.017.
84. Agawane SM, Nagarkar JM. Nano ceria catalyzed synthesis of a-aminophosphonates under ultrasonication. Tetrahedron Lett. 2011;52(27):3499-504. https://doi.org/10.1016/j.tetlet.2011.04.112.

85. Choudhury B, Choudhury A. Ce 3+ and oxygen vacancy mediated tuning of structural and optical properties of $\mathrm{CeO}_{2}$ nanoparticles. Mater Chem Phys. 2012;131(3):666-71. https://doi.org/10.1016/j.matchemphy s.2011.10.032.

86. Hayes BL. Recent advances in microwave-assisted synthesis. Aldrichim Acta. 2004;37:66-76.

87. Lew A, Krutzik PO, Hart ME, Chamberlin AR. Increasing rates of reaction: microwave-assisted organic synthesis for combinational chemistry. J Comb Chem. 2002;4(2):95-105.

88. Gao F, Lu Q, Komarneni S. Fast synthesis of cerium oxide nanoparticles and nanorods. J Nanosci Nanotechnol. 2006;6(12):3812-9.

89. Tao Y, Gong FH, Wang H, Wu HP, Tao GL. Microwave-assisted preparation of cerium dioxide nanocubes. Mater Chem Phys. 2008;112(3):973-6.

90. Shirke BS, Patil AA, Hankare PP, Garadkar KM. Synthesis of cerium oxide nanoparticles by microwave technique using propylene glycol as a stabilizing agent. J Mater Sci Mater Electron. 2011;22(2):200-3.

91. Soren S, Jena SR, Samanta L, Parhi P. Antioxidant potential and toxicity study of the cerium oxide nanoparticles synthesized by microwavemediated synthesis. Appl Biochem Biotechnol. 2015;177(1):148-61.

92. Aruna ST, Mukasyan AS. Combustion synthesis and nanomaterials. Curr Opin Solid State Mater Sci. 2008;12(3-4):44-50. https://doi. org/10.1016/j.cossms.2008.12.002.

93. Shi S, Hossu M, Hall R, Chen W. Solution combustion synthesis, photoluminescence and $\mathrm{X}$-ray luminescence of Eu-doped nanoceria $\mathrm{CeO}_{2}$ :Eu. J Mater Chem. 2012;22(44):23461-7.

94. Jamshidijam M, Mangalaraja RV, Akbari-Fakhrabadi A, Ananthakumar S, Chan SH. Effect of rare earth dopants on structural characteristics of nanoceria synthesized by combustion method. Powder Technol. 2014;253:304-10. https://doi.org/10.1016/j.powtec.2013.10.032.

95. Wu J, Shi S, Wang X, Li J, Zong R, Chen W. Controlled synthesis and optimum luminescence of $\mathrm{Sm} 3+$-activated nano/submicroscale ceria particles by a facile approach. J Mater Chem C. 2014;2(15):2786-92.

96. Ravishankar TN, Ramakrishnappa T, Nagaraju G, Rajanaika H. Synthesis and characterization of $\mathrm{CeO}_{2}$ nanoparticles via solution combustion method for photocatalytic and antibacterial activity studies. ChemistryOpen. 2015;4(2):146-54.

97. Singh RN, Awasthi R. New and future developments in catalysis: Chapter 16. Alcohol fuel cells. New York: Elsevier Inc:; 2013.

98. Malik MA, Wani MY, Hashim MA. Microemulsion method: a novel route to synthesize organic and inorganic nanomaterials 1 st nano update. Arab J Chem. 2012;5(4):397-417. https://doi.org/10.1016/j.arabj c.2010.09.027.

99. Patil S, Kuiry SC, Seal S, Vanfleet R. Synthesis of nanocrystalline ceria particles for high temperature oxidation resistant coating. J Nanoparticle Res. 2002:4:433-8.

100. Das M, Patil S, Bhargava N, Kang JF, Riedel LM, Seal S, et al. Auto-catalytic ceria nanoparticles offer neuroprotection to adult rat spinal cord neurons. Biomaterials. 2007;28(10):1918-25.

101. Sathyamurthy S, Leonard KJ, Dabestani RT, Paranthaman MP. Reverse micellar synthesis of cerium oxide nanoparticles. Nanotechnology. 2005;16(9):1960-4.

102. Huang Y, Cai Y, Qiao D, Liu H. Morphology-controllable synthesis and characterization of $\mathrm{CeO}_{2}$ nanocrystals. Particuology. 2011;9(2):170-3. https://doi.org/10.1016/j.partic.2010.07.023.

103. Tiseanu C, Parvulescu VI, Boutonnet M, Cojocaru B, Primus PA, Teodorescu CM, et al. Surface versus volume effects in luminescent ceria nanocrystals synthesized by an oil-in-water microemulsion method. Phys Chem Chem Phys. 2011;13(38):17135-45.

104. Rao BG, Mukherjee D, Reddy BM. Novel approaches for preparation of nanoparticles. New York: Elsevier Inc:; 2017. p. 1-36. https://doi. org/10.1016/B978-0-323-46142-9/00001-3.

105. YU T, Joo J, Park Y II, Hyeon T. Large-scale nonhydrolytic sol-gel synthesis of uniform-sized ceria nanocrystals with spherical, wire, and tadpole shapes. Angew Chemie Int Ed. 2005;44(45):7411-4.

106. Li L, Yang HK, Moon BK, Fu Z, Guo C, Jeong JH, et al. Photoluminescence properties of $\mathrm{CeO}_{2}$ : Eu3 + nanoparticles synthesized by a sol-gel method. J Phys Chem C. 2008;113:610-7. 
107. Gnanam $\mathrm{S}$, Rajendran V. Synthesis of $\mathrm{CeO}_{2}$ or a $-\mathrm{Mn}_{2} \mathrm{O}_{3}$ nanoparticles via sol-gel process and their optical properties. J Sol-Gel Sci Technol. 2011;58(1):62-9.

108. Wang Z, Quan Z, Lin J. Remarkable changes in the optical properties of $\mathrm{CeO}_{2}$ nanocrystals induced by lanthanide ions doping. Inorg Chem. 2007;46(13):5237-42.

109. Kar S, Patel C, Santra S. Direct room temperature synthesis of valence state engineered ultra-small ceria nanoparticles: investigation on the role of ethylenediamine as a capping agent. J Phys Chem C. 2009;113(12):4862-7.

110. Yu T, Lim B, Xia Y. Aqueous-phase synthesis of single-crystal ceria nanosheets. Angew Chemie Int Ed. 2010;49(26):4484-7.

111. Lan YP, Sohn HY. Nanoceria synthesis in molten $\mathrm{KOH}-\mathrm{NaOH}$ mixture: characterization and oxygen vacancy formation. Ceram Int. 2018;44(4):3847-55. https://doi.org/10.1016/j.ceramint.2017.11.172.

112. Takai O. Solution plasma processing (SPP). Pure Appl Chem. 2008;80(9):2003-11.

113. Kim SC, Kim JW, Yoon GJ, Nam SW, Lee SY. Antifungal effects of 3D scaffold type gelatin/Ag nanoparticles biocomposite prepared by solution plasma processing. Curr Appl Phys. 2013;13(1):S48-53. https://doi. org/10.1016/j.cap.2013.01.035.

114. Davoodbasha MA, Park BR, Rhee WJ, Lee SY, Kim JW. Antioxidant potentials of nanoceria synthesized by solution plasma process and its biocompatibility study. Arch Biochem Biophys. 2018;645:42-9. https:// doi.org/10.1016/j.abb.2018.02.003.

115. Patil S, Reshetnikov S, Haldar MK, Seal S, Mallik S. Surface-derivatized nanoceria with human carbonic anhydrase II inhibitors and fluorophores: a potential drug delivery device. J Phys Chem C. 2007;111(24):8437-42

116. Das J, Choi Y, Han JW, Musa A, Reza T, Kim J. Nanoceria-mediated delivery of doxorubicin enhances the anti-tumour efficiency in ovarian cancer cells via apoptosis. Sci Rep. 2017;7(1):9513. https://doi.org/10.1038/ s41598-017-09876-w.

117. Zholobak NM, Ivanov VK, Shcherbakov AB. Interaction of nanoceria with microorganisms. Nanobiomaterials in antimicrobial therapy: applications of nanobiomaterials. New York: Elsevier Inc.; 2016. p. 419-50. https ://doi.org/10.1016/B978-0-323-42864-4.00012-9.

118. Thill A, Zeyons O, Spalla O, Chauvat F, Rose J, Auffan M, et al. Cytotoxicity of $\mathrm{CeO}_{2}$ nanoparticles for Escherichia coli. Physico-chemical insight of the cytotoxicity mechanism. Environ Sci Technol. 2006;40(19):6151-6.

119. Rodea-Palomares I, Gonzalo S, Santiago-Morales J, Leganés F, García-Calvo E, Rosal R, et al. An insight into the mechanisms of nanoceria toxicity in aquatic photosynthetic organisms. Aquat Toxicol. 2012;122-123:133-43.

120. Wason MS, Colon J, Das S, Seal S, Turkson J, Zhao J, et al. Sensitization of pancreatic cancer cells to radiation by cerium oxide nanoparticleinduced ROS production. Biol Med. 2013;9(4):558-69. https://doi. org/10.1016/j.nano.2012.10.010

121. Dar MA, Gul R, Alfadda AA, Karim MR, Kim DW, Cheung CL, et al. Sizedependent effect of nanoceria on their antibacterial activity towards Escherichia coli. Sci Adv Mater. 2017:9:1248-53.

122. Alpaslan E, Geilich BM, Yazici H, Webster TJ. PH-controlled cerium oxide nanoparticle inhibition of both gram-positive and gram-negative bacteria growth. Sci Rep. 2017;7:1-12. https://doi.org/10.1038/srep45859.

123. Kartsonakis IA, Liatsi P, Daniilidis I, Kordas G. Synthesis, characterization, and antibacterial action of hollow ceria nanospheres with/without a conductive polymer coating. J Am Ceram Soc. 2008;91(2):372-8.

124. Krishnamoorthy K, Veerapandian M, Zhang LH, Yun K, Kim SJ. Surface chemistry of cerium oxide nanocubes: toxicity against pathogenic bacteria and their mechanistic study. J Ind Eng Chem. 2014;20(5):3513-7. https://doi.org/10.1016/j.jiec.2013.12.043.

125. Kuang Y, He X, Zhang Z, Li Y, Zhang H, Ma Y, et al. Comparison study on the antibacterial activity of nano- or bulk-cerium oxide. J Nanosci Nanotechnol. 2011:11(5):4103-8.

126. Shah V, Shah S, Shah H, Rispoli FJ, McDonnell KT, Workeneh S, et al. Antibacterial activity of polymer coated cerium oxide nanoparticles. PLOS ONE. 2012;7(10):1-13.

127. Li Y, Zhang W, Niu J, Chen Y. Mechanism of photogenerated reactive oxygen species and correlation with the antibacterial properties of engineered metal-oxide nanoparticles. ACS Nano. 2012;6(6):5164-73.
128. Cuahtecontzi-Delint R, Mendez-Rojas MA, Bandala ER, Quiroz MA, Recillas S, Sanchez-Salas JL. Enhanced antibacterial activity of $\mathrm{CeO}_{2}$ nanoparticles by surfactants. Int J Chem React Eng. 2013;11(2):781-5.

129. Unnithan AR, Ramachandra Kurup Sasikala A, Sathishkumar Y, Lee YS, Park CH, Kim CS. Nanoceria doped electrospun antibacterial composite mats for potential biomedical applications. Ceram Int. 2014:40(8):12003-12. https://doi.org/10.1016/j.ceramint.2014.04.038.

130. Reshma P, Ashwini K. Cerium oxide nanoparticles: synthesis, characterization and study of antimicrobial activity. J Nanomater Mol Nanotechnol. 2017;06(03):2-6.

131. dos Santos C, Passos Farias I, Reis Albuquerque A, Silva P, CostaOne $\mathrm{G}$, Sampaio F. Antimicrobial activity of nano cerium oxide (IV) $\left(\mathrm{CeO}_{2}\right)$ against Streptococcus mutans. BMC Proc. 2014;8(Suppl 4):P48.

132. Venkatesh KS, Gopinath K, Palani NS, Arumugam A, Jose SP, Bahadur SA, et al. Plant pathogenic fungus $F$ solani mediated biosynthesis of nanoceria: antibacterial and antibiofilm activity. RSC Adv. 2016;6(48):42720-9.

133. Magdalane CM, Kaviyarasu K, Vijaya JJ, Siddhardha B, Jeyaraj B. Photocatalytic activity of binary metal oxide nanocomposites of $\mathrm{CeO}_{2} /$ CdO nanospheres: investigation of optical and antimicrobial activity. J Photochem Photobiol B Biol. 2016;163:77-86. https://doi.org/10.1016/j. jphotobiol.2016.08.013.

134. Colon J, Hsieh N, Ferguson A, Kupelian P, Seal S, Jenkins DW, et al. Cerium oxide nanoparticles protect gastrointestinal epithelium from radiation-induced damage by reduction of reactive oxygen species and upregulation of superoxide dismutase 2. Nanomed Nanotechnol Biol Med. 2010;6(5):698-705. https://doi.org/10.1016/.nano.2010.01.010.

135. Chen S, Hou Y, Cheng G, Zhang C, Wang S, Zhang J. Cerium oxide nanoparticles protect endothelial cells from apoptosis induced by oxidative stress. Biol Trace Elem Res. 2013;154(1):156-66.

136. Rubio L, Annangi B, Vila L, Hernández A, Marcos R. Antioxidant and antigenotoxic properties of cerium oxide nanoparticles in a pulmonary-like cell system. Arch Toxicol. 2016;90(2):269-78.

137. Kim SJ, Chung BH. Antioxidant activity of levan coated cerium oxide nanoparticles. Carbohydr Polym. 2016;150:400-7. https://doi. org/10.1016/j.carbpol.2016.05.021.

138. Ranjbar A, Soleimani AsI S, Firozian F, Heidary Dartoti H, Seyedabadi $\mathrm{S}$, Taheri Azandariani $\mathrm{M}$, et al. Role of cerium oxide nanoparticles in a paraquat-induced model of oxidative stress: emergence of neuroprotective results in the brain. J Mol Neurosci. 2018;66(3):420-7.

139. Pagliari F, Mandoli C, Forte G, Magnani E, Pagliari S, Nardone G, et al. Cerium oxide nanoparticles protect cardiac progenitor cells from oxidative stress. ACS Nano. 2012;6(5):3767-75.

140. Ciofani G, Genchi GG, Mazzolai B, Mattoli V. Transcriptional profile of genes involved in oxidative stress and antioxidant defense in PC12 cells following treatment with cerium oxide nanoparticles. Biochim Biophys Acta Gen Subj. 2014;1840(1):495-506. https://doi.org/10.1016/j.bbage n.2013.10.009.

141. Marino A, Tonda-Turo C, De Pasquale D, Ruini F, Genchi G, Nitti S, et al. Gelatin/nanoceria nanocomposite fibers as antioxidant scaffolds for neuronal regeneration. Biochim Biophys Acta Gen Subj. 2017;1861 (2):386-95. https://doi.org/10.1016/j.bbagen.2016.11.022.

142. Lin W, Huang YW, Zhou XD, Ma Y. Toxicity of cerium oxide nanoparticles in human lung cancer cells. Int J Toxicol. 2006;25(6):451-7.

143. Hijaz M, Das S, Mert I, Gupta A, Al-wahab Z, Tebbe C, et al. Folic acid tagged nanoceria as a novel therapeutic agent in ovarian cancer. BMC Cancer. 2016;16(1):220. https://doi.org/10.1186/s12885-016-2206-4.

144. Jana SK, Banerjee P, Das S, Seal S, Chaudhury K. Redox-active nanoceria depolarize mitochondrial membrane of human colon cancer cells. J nanoparticle Res. 2014;16(6):2441.

145. Kumari M, Singh SP, Chinde S, Rahman MF, Mahboob M, Grover P. Toxicity study of cerium oxide nanoparticles in human neuroblastoma cells. Int J Toxicol. 2014;33(2):86-97.

146. Nourmohammadi E, Khoshdel-sarkarizi H, Nedaeinia R, Sadeghnia HR, Hasanzadeh L, Darroudi M, et al. Evaluation of anticancer effects of cerium oxide nanoparticles on mouse fibrosarcoma cell line. J Cell Physiol. 2019;234(4):4987-96.

147. Muhammad F, Wang A, Qi W, Zhang S, Zhu G. Intracellular antioxidants dissolve man-made antioxidant nanoparticles: using redox vulnerability of nanoceria to develop a responsive drug delivery system. ACS Appl Mater Interfaces. 2014;6(21):19424-33. 
148. Li H, Liu C, Zeng YP, Hao YH, Huang JW, Yang ZY, et al. Nanoceriamediated drug delivery for targeted photodynamic therapy on drugresistant breast cancer. ACS Appl Mater Interfaces. 2016;8(46):31510-23.

149. Das J, Han JW, Choi YJ, Song H, Cho SG, Park C, et al. Cationic lipidnanoceria hybrids, a novel nonviral vector-mediated gene delivery into mammalian cells: Investigation of the cellular uptake mechanism. Sci Rep. 2016;6(1):29197. https://doi.org/10.1038/srep29197.

150. IDF Diabetes Atlas 8th Edition. 2017.

151. Manna P, Das J, Sil PC. Role of sulfur containing amino acids as an adjuvant therapy in the prevention of diabetes and its associated complications. Curr Diabetes Rev. 2013;9:237-48.

152. Khurana A, Tekula S, Godugu C. Nanoceria suppresses multiple low doses of streptozotocin-induced Type 1 diabetes by inhibition of Nrf2/NF-kB pathway and reduction of apoptosis. Nanomedicine. 2018;13(15):1905-22.

153. Shokrzadeh M, Abdi H, Asadollah-Pour A, Shaki F. Nanoceria attenuated high glucose-induced oxidative damage in HepG2 cells. Cell J. 2016;18(1):97-102.

154. Artimani T, Amiri I, Soleimani Asl S, Saidijam M, Hasanvand D, Afshar S. Amelioration of diabetes-induced testicular and sperm damage in rats by cerium oxide nanoparticle treatment. Andrologia. 2018;50(9):e13089.

155. Hasanvand D, Amiri I, Soleimani Asl S, Saidijam M, Shabab N, Artimani T. Effects of CeO 2 nanoparticles on the HO-1, NQO1, and GCLC expression in the testes of diabetic rats. Can J Physiol Pharmacol. 2018:96(9):963-9.

156. Crowther CA, Hiller JE, Moss JR, MCPhee AJ, Jeffries WS, Robinson JS. Effect of treatment of gestational diabetes mellitus on pregnancy outcomes. N Engl J Med. 2005;352(24):2477-86.

157. Vafaei-Pour Z, Shokrzadeh M, Jahani M, Shaki F. Embryo-protective effects of cerium oxide nanoparticles against gestational diabetes in mice. Iran J Pharm Res. 2018:17(3):964-75.

158. Pourkhalili N, Hosseini A, Nili-Ahmadabadi A, Rahimifard M, NavaeiNigjeh M, Hassani S, et al. Improvement of isolated rat pancreatic islets function by combination of cerium oxide nanoparticles/sodium selenite through reduction of oxidative stress. Toxicol Mech Methods. 2012;22(6):476-82.

159. Hosseini A, Baeeri M, Rahimifard M, Navaei-Nigjeh M, Mohammadirad A, Pourkhalili N, et al. Antiapoptotic effects of cerium oxide and yttrium oxide nanoparticles in isolated rat pancreatic islets. Hum Exp Toxicol. 2013;32(5):544-53.

160. Das S, Chigurupati S, Dowding J, Munusamy P, Baer DR, McGinnis JF, et al. Therapeutic potential of nanoceria in regenerative medicine. MRS Bull. 2014;39(11):976-83.

161. Zhang Q, Ge K, Ren H, Zhang C, Zhang J. Effects of cerium oxide nanoparticles on the proliferation, osteogenic differentiation and adipogenic differentiation of primary mouse bone marrow stromal cells in vitro. J Nanosci Nanotechnol. 2015;15(9):6444-51.

162. Gagnon J, Fromm KM. Toxicity and protective effects of cerium oxide nanoparticles (Nanoceria) depending on their preparation method, particle size, cell type, and exposure route. Eur J Inorg Chem. 2015;2015(27):4510-7.

163. Aalapati S, Ganapathy S, Manapuram S, Anumolu G, Prakya BM. Toxicity and bio-accumulation of inhaled cerium oxide nanoparticles in CD1 mice. Nanotoxicology. 2014;8(7):786-98.

164. Wu J, Ma Y, Ding Y, Zhang P, He X, Zhang Z. Toxicity of two different size ceria nanoparticles to mice after repeated intranasal instillation. J Nanosci Nanotechnol. 2018;19(5):2474-82.

165. Kumari M, Kumari SI, Grover P. Genotoxicity analysis of cerium oxide micro and nanoparticles in Wistar rats after 28 days of repeated oral administration. Mutagenesis. 2014;29(6):467-79.

166. Ranjbar A, Ghasemi H, Abedian A, Kheiripour N. Cerium oxide nanoparticle modulates hepatic damage, inflammatory and oxidative stress biomarkers in a dose-dependent manner : an in vivo study of rat liver. Nanomed J. 2018:5(4):245-50.

167. Gagnon C, Bruneau A, Turcotte P, Pilote M, Gagné F. Fate of cerium oxide nanoparticles in natural waters and immunotoxicity in exposed rainbow trout. J Nanomed Nanotechnol. 2018;9(2):489.

\section{Publisher's Note}

Springer Nature remains neutral with regard to jurisdictional claims in published maps and institutional affiliations.
Ready to submit your research? Choose BMC and benefit from:

- fast, convenient online submission

- thorough peer review by experienced researchers in your field

- rapid publication on acceptance

- support for research data, including large and complex data types

- gold Open Access which fosters wider collaboration and increased citations

- maximum visibility for your research: over $100 \mathrm{M}$ website views per year

At BMC, research is always in progress.

Learn more biomedcentral.com/submissions 